\title{
The Effects of Quantitative Easing on the Volatility of the Gilt-Edged Market
}

\author{
By
}

James M. Steeley and Alexander Matyushkin

\begin{abstract}
We model the effects of quantitative easing on the volatility of returns to individual gilts, examining both the effects of QE overall and of the specific days of asset purchases. The action of QE successfully neutralized the six fold increase in volatility that had been experienced by gilts since the start of the financial crisis. The volatility of longer term bonds reduced more quickly than the volatility of short to medium term bonds. The reversion of the volatility of shorter term bonds to pre-crisis levels was found to be more sensitive to the specific operational actions of QE, particularly where they experienced relatively greater purchase activity.
\end{abstract}

JEL: G12, E44, E52

Keywords: Quantitative Easing, Gilts, UK Bonds, Volatility, Bond Investors

James M. Steeley, Aston Business School, Birmingham, B4 7ET, UK. Tel: 44-121-204-3248. Email: j.m.steeley@aston.ac.uk (corresponding author). Alexander Matyushkin, United Capital Partners Advisory, Moscow, Russia. Email: matyushkin.alexander@gmail.com. Any views expressed are those of the authors and do not necessarily reflect those of United Capital Partners. 


\section{Introduction}

The gilt-edged market, the market for UK government bonds, has been the main instrument through which the Bank of England has operated its policy of quantitative easing, a programme of expansionary monetary policy through asset purchases funded by electronic money creation. While there have been a number of studies of the effects of quantitative easing on the UK bond market, these have focussed exclusively on determining the success or otherwise of this unconventional form of monetary policy. ${ }^{1}$ However, the gilt-market is also a major vehicle for those seeking long term fixed interest investments, for example pension funds and life insurance companies. This study examines the effects of quantitative easing from a bond investor's viewpoint and looks in particular at whether the volatility in the market has been affected by the asset purchase operations. This is important because if investors perceive volatility to have risen, they may require a greater premium for holding longer term gilts, raising the cost of financing government expenditure, and worsening the very economic outlook that the quantitative easing is designed to improve. Moreover, the costs to financial institutions and others using fixed income derivatives for hedging purposes will be directly affected by significant changes in the volatility of the underlying bonds.

The quantitative easing programme in the UK can be divided into three phases of activity. The first phase, QE1, between March 2009 and January 2010, saw £200 billion spent to purchase assets, mostly gilts. By the end of QE1 $40 \%$ of the stock outstanding of 3-10 year maturity bonds were purchased, $50 \%$ of the 10-25 year maturity bonds, and $15 \%$ of the more than 25 years maturity bonds were purchased. The purchases were conducted using a reverse auction process, auctions, whereby counterparties submitted prices at which they offered to sell specific quantities of individual gilts. Non-competitive (quantity only) bids were also permitted, with successful bids paying the average accepted competitive price. Other assets such as commercial paper and corporate bonds were also purchased by the Bank but in significantly smaller quantities, and these were being sold back into the market by December 2009. At the meeting of the Monetary Policy Committee held on the $4^{\text {th }}$ of February 2010, the members decided not to increase the limit for asset purchases further. In October 2011 the second round of

1. For example, Meier (2009), Joyce et al (2011), Glick and Leduc (2012), Meaning and Zhu (2011), Joyce and Tong (2012) and Breedon et al (2012). These together with studies looking at the US experience and the wider economic effects of QE are surveyed in Joyce et al (2012) and Martin and Milas (2012). 
quantitative easing began (QE2) after the members of the Monetary Policy Committee voted to increase the limit of asset purchases further by $£ 75$ billion. A further increase of $£ 50$ billion was announced in February 2012 and the purchases were accomplished by the $2^{\text {nd }}$ of May 2012. After only a two-month gap the QE asset purchase facility was restarted again. On the $5^{\text {th }}$ of July 2012 , the MPC announced a further $£ 50$ billion of gilt purchases, to be completed by November 2012, this phase being identified as QE3. ${ }^{2}$

In an efficient financial market, macroeconomic news should be fully and instantaneously reflected in market prices (and returns). Ross (1989) used a no-arbitrage martingale theoretical asset pricing framework to establish that asset price volatility represents the rate of information flow into an efficient market. Higher volatility implies a higher rate of flow of information into prices and thus a more efficient market. The relationship between financial market volatility and macroeconomic news, in particular, is developed in the theoretical work of Veronesi (1999). In this model, if the uncertainty surrounding macroeconomic fundamentals is high, then news causes asset prices to move much more than when this uncertainty is lower.

Empirical investigation of the link between information flow, specifically macroeconomic news, and bond market return volatility commenced with the study by Jones, Lamont and Lumsdaine (1998). ${ }^{3}$ The authors use high frequency data and apply a GARCH model to analyze the effect of macroeconomic news announcements on bond market volatility in the US They find that Treasury bond returns and volatility are significantly higher on the announcement days of US macroeconomic data such as the unemployment statistics and the producer price index. However, they also show that the news effect is short-lived, so that the impact on volatility disappears soon after the announcement. De Goeij and Marquering (2006) also examine daily returns on US Treasury bonds, between 1982 and 2004, but use a GARCH model that includes a threshold variable to distinguish the effects of positive and negative news announcements. They find negative news tends to have a greater impact on volatility. Arnold and Vrugt (2010) study the relationship between macroeconomic uncertainty, measured by the log

2. Although the QE2 and QE3 phases have been separately distinguished in some recent survey papers, Joyce et al (2012) and Martin and Milas (2012), the short gap between them may mean that this distinction is not preserved in the future.

3. While we confine this review to studies of macroeconomic news and bond market volatility, there are longer established parallel literatures examining the effects of conventional monetary policy surprises and other macroeconomic news on returns in stock and bond markets and volatility in stock markets both within and across countries, for example, Balduzzi et al., 2001, Bomfim, 2003, Ederington and Lee, 1993, Graham et al., 2003, Kearney and Lombra, 2004, Nikkinen and Sahlström, 2001, 2004a, 2004b, 2006. 
sum of absolute residuals from an AR(1) process applied to several different macroeconomic variables, and bond volatility measured by the quarterly standard deviation of returns. They find much stronger links between uncertainty and volatility than in the previous studies, also providing strong support for the theoretical framework of Veronesi (1999). Huang and Lu (2008) use a principal components analysis to decompose macroeconomic variables into real and monetary factors. They find that while real factors influence volatility across the maturity spectrum, monetary variables influence only the volatility of short and medium term bonds. Nowak et al (2011) show that the response of volatility to macroeconomic news is considerably slower in the bond markets of emerging countries relative to those of more mature economies. Abad and Chulia (2013) find that the volatility of European bond markets increase following monetary policy surprises. Won et al (2013) examine the effect of unanticipated changes in a country's credit spread on the volatility in its bond market, looking in particular at the markets in Brazil, Russia, China and Turkey. They document an asymmetry in the relation wherein increases in credit spreads have a greater impact on volatility than decreases in credit spreads. They also identified a feedback effect from volatility to credit spreads, but only during the financial crisis, indicating that credit spreads and bond market volatility could interact to generate further market instability.

While there have been no studies looking directly at the effect of QE on bond market volatility, there have been some studies that have considered the effect of QE on equity market volatility. Tan and Kohli (2011) examine the volatility of the US stock market over the period 2008 to 2011, which encompasses the US QE1 and QE2 phases. They examine three models of volatility, an AR(1) process and a modified constant elasticity of variance model, both applied to the VIX measure of implied volatility for the S\&P500 index, and the conditional volatility from a GARCH $(1,1)$ model applied to the returns to the S\&P500 index. They find that the onset of QE led to a significant drop in stock index volatility that then reverted to previous levels following the ending of a phase of QE. Joyce et al (2011) examine the behavior of the option-implied volatility of the FTSE100 index between January 2009 and June 2010, a period encompassing the UK QE1 phase. They found that the twelve-month implied volatility fell by around $40 \%$ during 2009. They also constructed an option-implied probability distribution for the FTSE100 returns and found that it narrowed between February 2009 and February 2010, with the (lower) tail risk falling considerably. 
The earliest study of the conditional volatility of UK government bonds is Steeley (1992) who applied the time varying volatility model of Taylor (1986) and Taylor and Kingsman (1979) to the returns of individual gilts around the time of the 1986 Big Bang deregulation of the UK financial markets. This model uses an exponentially-weighted average of the absolute value of the deviation of returns from their average to create a sequence of conditional volatility forecasts. He showed that the volatility of gilts declined in the aftermath of the deregulation. Longer term historical perspectives are provided by both Anderson and Breedon (2000) and Johnson and Young (2002) who studied the periods 1946-1995 and 1957 to 2000, respectively. Both studies document a significant increase in UK bond market volatility between 1972 and 1975, and a gradual downward trend thereafter. Steeley and Ahmad (2002) focus on the effects of the flight to quality following the Asian crisis and the dot.com boom and bust in equity markets around the end of the last millennium. They find a significant decrease in the volatility of the UK bond market at this time as the market enjoyed "safe-haven" status.

This paper contributes to and extends these existing literatures in several ways. First, it is the first study to directly consider the impact of QE on the volatility of the UK bond market. Second, by focussing on the experience of individual bonds, it examines QE from the perspective of bond market investors. Third, by contrast to most prior studies of the effects of QE in the UK that consider only the first round of QE, between 2009 and 2010, this study additionally considers the more recent second and third rounds. Fourth, there have been very few studies of the volatility of the UK bond market, and none considering the time interval since 2001, and so this study provides further and more current evidence of the behavior of volatility in this market.

The key findings of this paper are the following. Using a GARCH based model of conditional return volatility, we document a significant increase in bond market volatility prior to the commencement of QE. This appears to begin at the point that the Bank of England offered special liquidity support to the Northern Rock bank in September 2007. This increase in volatility was as much as 600 percent for longer term government bonds. The first phase of QE led to a gradual reduction in bond market volatility, back to pre-crisis levels for ultra-short and long term bonds, but to levels still significantly above the pre-crisis levels for short and medium maturity bonds. The subsequent phases of QE led to further significant reductions in volatility, so that all bonds had volatility back at the pre-crisis levels or lower. Using an event study 
methodology, we also uncover a pre-announcement drift downwards in the volatility of gilts across the month ahead of the Bank of England's first announcement relating to QE, its intention to establish an asset purchase facility. Using cross section regressions, we find that bonds that experienced relatively more purchase auction activity saw relatively less reduction in volatility during the first phase of QE. However, this effect diminishes through the later QE periods, and can be counteracted by a large excess supply of an individual gilt for purchase. By examining the relationship between the UK money supply and gilt volatility, we are able to conclude that the effects of $\mathrm{QE}$ on gilt volatility were unlikely to be arising through a portfolio rebalancing channel. Overall, the phases of QE and specific purchase auction activity had significant effects on the volatility of gilts, but this has been to successfully neutralize the increase in volatility that was experienced in the preceding two years. This likely indicates that the effects of QE on gilt volatility were mostly operating through a signalling channel, providing a calming influence on the market.

This rest of the paper proceeds as follows. Section 2 describes the data sources and sample periods, and presents the empirical methods that will be used. Section 3 presents the results of the analysis, and Section 4 offers some conclusions and a summary of the results.

\section{Data and Methods}

We use a sample of 24 UK government bonds that collectively span the period January $1^{\text {st }}, 2004$ to May $10^{\text {th }}, 2013$. This is a period of 2362 trading days. The bonds selected comprise all the conventional style gilts that had at least 2 years of data available during the sample period and a maturity of at least three years ahead of the start of the QE1 phase. The three years to maturity limit ensures that a bond meets the two years of data requirement and is not affected by a "pullto-par" effect on price as the bond approaches maturity. ${ }^{4}$ The bonds range in maturity from 3 years out to the year 2055, with all maturity regions well populated with bonds. Bonds that were issued or redeemed during the sample period were included provided they met the inclusion criteria above. In addition to the individual bond data, we also examine the Financial Times Actuaries long gilt index to see whether effects found in individual bonds are repeated at the level of the index. Daily closing clean bond price data and index data are collected from

4. Steeley and Ahmad (2002) and Steeley (1992) present evidence of a pull-to-par effect that can distort the time series statistics of very short-term to maturity bond returns. 
Datastream, and are used to calculate returns as the log daily change in clean price for the bonds, and the log daily change in the index level for the index.

\subsection{Modelling the effects of $Q E$ on volatility}

We use the generalized autoregressive conditional heteroskedasticity (GARCH) family of statistical processes (Engle, 1982 and Bollerslev, 1986) to model jointly the conditional mean and variance of individual bond returns. In this model, the conditional variance is a linear function of a number of squared previous errors and a number of previous conditional variances. The specific model that will be applied to each of the time series of bond returns is

$$
\begin{gathered}
r_{j, t}=c_{j}+\phi_{j} r_{j, t-1}+\sum_{i=1}^{14} \gamma_{i, j} D_{i, t}+\varepsilon_{j, t}-\theta_{j} \varepsilon_{j, t-1} \quad j=1,2, \ldots, 24 \\
\varepsilon_{j, t} \mid r_{j, t-1}, r_{j, t-2}, \ldots \sim N\left(0, h_{j, t}\right) \\
h_{j, t}=\omega_{j}+\alpha_{j} \varepsilon_{j, t-1}^{2}+\beta_{j} h_{j, t-1}+\lambda_{j} I_{t} \varepsilon_{j, t-1}^{2}+\sum_{i=1}^{14} \kappa_{i, j} D_{i, t}
\end{gathered}
$$

where $r_{j, t}$ is the return (log change in closing clean price) of bond $j$ at time $t$. The specifications in equation (1) are standard and have an $\operatorname{ARMA}(1,1)$ process for the conditional mean, and a $\operatorname{GARCH}(1,1)$ specification for the conditional variance. ${ }^{5}$ The variable $I_{t}$ is an indicator variable that takes the value 1 if $\varepsilon_{j, t-1}<0$ and is zero otherwise. This variable, initially proposed by Glosten et al (1993), permits the conditional volatility to respond asymmetrically to positive and negative news. Where this interaction variable does not significantly improve the model, the standard GARCH(1,1) model is used.

A set of 14 dummy (indicator) variables is introduced into both the conditional mean and conditional variance specifications to capture differences arising from $\mathrm{QE}$ and other bond market events. The first dummy variable takes the value 1 during the first phase of QE, and zero at all

5. We estimated the model under the assumption that the error distribution is normal. We also estimated the model with the Generalized Error Distribution, GED, see Nelson (1991). Despite observing non-normality (primarily excess kurtosis) in the individual bond return distributions, the estimated GED tail parameter was indistinguishable from its value under normality for many of the bonds, and the estimated coefficients underwent negligible quantitative changes and no qualitative changes. We also tested for the presence of direct feedback from the conditional variance equation to the conditional mean equation, the GARCHM model, see Engle et al, (1987). While this model was initially developed within a model of the yield curve, we could not reject the hypothesis that the "in-mean" term did not improve the model for individual bond returns. 
other times. The second and third dummy variables are constructed similarly to indicate the second and third phases of QE. We also include four day of the week dummy variables. As our sample period begins prior to the financial crisis, we also include an indicator variable for the period of the crisis leading up to QE1. We start this period on September 14, 2007, the date that Northern Rock bank received special liquidity support from the Bank of England to help with its exposure to the sub-prime lending market.

In addition to the broad indicators for the QE phases, we also include an indicator for the specific days upon which the Bank of England operated its asset purchase facility (APF) and bought gilts through purchase auctions in the market during the QE phases. This is aimed at determining whether the effects of the QE phases were more than just the cumulative response to a set of purchases auctions. We also add a further indicator variable that takes the value 1 if the particular bond being modelled was the one subject to QE purchase on that day. This permits us to determine whether the effects of the asset purchases are asset specific or cross over to other bonds. The data on the bonds being purchased and the dates of the APF operations were obtained from the Bank of England's website.

We also account for the impact of announcements relating to monetary policy and in particular QE. We do this by including an indicator variable that takes the value of one on days of specific announcements relating to QE and takes the value zero otherwise. The details of these announcements are given in Table 1. We include a further variable that takes the value one on days that the MPC announced the results of their monthly meetings, and is zero otherwise.

While some previous studies of QE have considered an event study approach to examining the effects of purchase auctions, for example, Joyce et al (2011) and Meaning and Zhu (2011), the clear dependence of their results on the event window length, pointed out by Martin and Milas (2012), suggests that there is value in examining other approaches. The regression approach that we adopt has the advantage of permitting multiple factors to be considered simultaneously. The previous event studies implicitly assume that the characteristics of the event windows are constant across bonds, whereas some bonds may have experienced issuance within the event window while others may not have had this happen. In October 2008, the UK Treasury's funding remit for the gilt market was raised by $£ 37 \mathrm{bn}$ to assist with the recapitalization the UK banking sector. This led to a huge increase in both gross and net issuance 
of gilts. This can be seen in Figure 1. From the financial year 2008-2009, gross annual issuance was three times its pre-crisis peak level. As this extra issuance continued through into the QE1 phase, and indeed continued throughout the sample period, it is essential to control for this other significant activity within the gilt market at this time. The relative size of issuance and APF activity over the sample can be seen in Figure 2, where it can be seen that there were occasions when the purchase activity outstripped the issuance activity. These two activities displayed a systematic pattern during the week, which can be seen in Figures 3 and 4, with Wednesday observing peaks for both issuance and purchases. To capture the effects of issuance, we construct two dummy variables, of a similar form to those created to capture the effects of bond purchase auctions. One of these variables takes the value one on a day on which bonds were issued and zero otherwise, and the other variable takes the value one if the particular bond is itself experiencing further issuance. Evidence that secondary offerings affect gilt prices can be found in Breedon and Ganley (2000), who studied the period 1997-98 and Ahmad and Steeley (2008), who studied the period 2001-2007. Both find that prices are bid down before an auction and rise strongly afterwards. Evidence that auction activity might affect volatility is provided by Hughes et al (2008), who show that weeks of US Treasury Bill auctions show greater volatility in the market than weeks without auctions.

Although our modeling framework is designed to capture the effects of QE on bond volatility controlling for differences in within the bonds themselves, it does not directly control for (non-QE) macro-level factors. Unlike financial market data, that is available at ever increasing frequencies, economic data is usually released on a monthly basis, sometimes quarterly. This presents a challenge to incorporating macro-level controls on financial market models that use higher frequency data, such as is the case here. The most readily available proxy variable for business conditions on a daily basis is the return on the stock market. To try to establish whether our methods and results are robust to changes in the general economic environment, we re-formulated the model in equation (1) with the inclusion of the stock market return included in both the mean and volatility equations. This made little difference to the sign, 
size and significance of estimated parameters and changed none of our conclusions. To preserve space, we present only the results of the model without the inclusion of the market return. ${ }^{6}$

\subsection{A volatility event study}

Although event studies typically focus on returns, specifically abnormal returns, and among the QE studies there is a clear dependence on the event window, it is nonetheless interesting to augment our regression approach with a volatility based event study. Specifically, we will examine whether the widely anticipated use of QE caused any change in bond market volatility before formal announcements relating to QE. Evidence that financial markets might anticipate monetary policy announcements has been found by Lucca and Moench (2011), who showed that US equities earned abnormal returns ahead of the Federal Open Market Committee's announcements of US monetary policy actions, a phenomenon they have labeled "pre-FOMC announcement drift". We examine four "events", the announcement of the start of each period of QE and, prior to this in January 2009, the announcement of the intention to establish an asset purchase facility by the Bank of England. The announcements are detailed in Table 1. We use windows of 10, 20 and 40 days prior to each of the announcements, and calculate the cumulative change in daily return volatility - measured by the squared return averaged across each of the gilts. To determine the significance of the cumulative average change in volatility, we compute t-tests following the same standard procedures as would be adopted were this instead an event study of cumulative average abnormal returns (CAAR).

\subsection{Explaining the impacts of QE on gilt volatility: Bond characteristics}

In addition to identifying whether the volatility of gilts is influenced by the phases of QE, announcements, events and specific purchase and issuance activity, we investigate what makes a particular bond more susceptible to having its volatility influenced by these factors. We do this by regressing the coefficients $\kappa_{i, j}$ (standardized by their regression standard error) from the time series model, equation (1), against the following cross-section characteristics of the bonds. ${ }^{7} \mathrm{We}$

6. The results including the market return are available on request. Later in this paper, however, we report on an analysis using monthly gilt volatility measures to understand the relation between changes in the money supply, as another macro-level factor, and gilt volatility.

7. The set of variables examined is similar to those used in the event studies of individual gilt QE purchase auctions, Joyce and Tong (2012), and of individual gilt secondary issues, Ahmad and Steeley (2008). 
include the bond's coupon rate and time to maturity as regressors. As short term yields were falling during the sample period, while the maturity of new bonds being issued was rising, coupon and maturity are moderately negatively correlated (-0.43). For the regressions that examine the sensitivity of volatility to the phases of QE, we also include a measure of the purchase activity that the bond experienced during the phases of QE. This regressor is the total volume of purchases by the Bank of England as a proportion of the average of stock of the gilt outstanding at the beginning of QE1 and the stock outstanding at the end of sample period. Each of the purchase auctions differed by the amount by which the offers to sell stock to the Bank exceeded the amount purchased by the Bank. This measure of excess supply is known as the Cover Ratio. A further measure of excess supply is the Tail, which is the amount by which the highest accepted ask price exceeds the (weighted) average accepted ask price. The smaller the tail, the greater the excess supply. We combine both of these measures into a single measure of excess supply by extracting the first principal component of the correlation between the two variables. This excess supply measure is then the fourth regressor included alongside coupon, maturity and purchase auction activity.

We use the same regressor variables to examine the sensitivity of volatility to the days of bond purchase activity. To examine the determinants of the sensitivity to announcements relating specifically to QE and of the announcements of the outcome of each MPC meeting, we again include coupon, maturity and the same measure of purchase activity. But now we replace the excess supply variable with a measure of the issuance activity that the bond experiences during the sample period. This is the change in the stock outstanding between the beginning and end of the sample period (or between the original and redemption dates if these are inside the limits of the sample period). To examine the determinants of volatility sensitivity to issuance activity, we re-use this issuance variable along with coupon and maturity as regressors. For these issuance based regressions, we replace the purchase activity regressor variable with a measure of the size of the issue at the beginning of the sample period. 


\subsection{Explaining the impacts of QE on gilt volatility: Monetary transmission}

Finally, we investigate whether the monetary transmission channels that might arise from QE could themselves be driving the volatility of the gilt market. Quantitative easing has three main channels through which it can affect the economy. The first is a signaling channel. The use of QE demonstrates a commitment to low interest rates and monetary easing more generally, and this is likely to boost investment and consumption. The second is a liquidity channel. In this case, the purchases of gilts from the banks, by the Bank of England, enhance their reserve levels, that should then facilitate greater lending to commercial activity. The third channel is a portfolio balance channel, whereby the purchases of gilts may lead to an increase in asset prices, which leads to both wealth effects and lower costs of capital, that in turn boosts the economy through increased investment and consumption. As well as the direct upward pressure on gilt prices that may arise from the Bank's purchases, there can arise an additional "ripple effect" to increase the prices of other assets if the sellers of the gilts do not regard the cash received as a perfect substitute for the gilts sold, and use the cash to purchase other assets. This process may continue until all asset prices have been bid upwards to rebalance asset portfolios to accommodate the increased cash balances. ${ }^{8}$

Both the changes in bank reserves through the liquidity channel and the portfolio rebalancing activity that arise as a consequence of central bank asset purchases are likely to influence the measured money supply. Indeed the electronic money creation used to finance the purchases represents a pure increase in the money supply. It is possible therefore that if bond volatility is responding to $\mathrm{QE}$ activity, it will show some correspondence to changes in the money supply. To determine whether there is a direct link between the money supply and gilt volatility, we undertake bivariate Granger-causality tests between the money supply and each of the individual gilt volatility series. A variable $x$ is said to Granger-cause a variable $y$ if past values of $x$ have a significance influence on the current value of $y$, after controlling for the influence of an equal number of past values of $y$, and the reverse is not observed. The significance of the past values of $x$ is usually established with a Wald test of the joint significance of a sub-set of regression coefficients. The monthly money supply data, UK M0, is

8. See Benford et al (2009) for more detail on how each of these QE transmission channels operates. 
obtained from the Bank of England's website. ${ }^{9}$ This is matched to monthly volatility measures for each of the individual gilts. These are calculated as the standard deviation of the daily returns to the gilt for the period in between each of the monthly money supply data releases.

We use the approach to testing for Granger-causality proposed by Toda and Yamamoto (1995). This first requires that the order of integration of each series is established. Then the variables are combined in a vector autoregression (VAR), which has a lag length determined by information criteria, and then adds additional lags to remove any remaining residual autocorrelation. Finally, to ensure that the Wald tests for non-causality have an asymptotic chisquared distribution when one or more of the variables may be non-stationary, $m$ additional lags are added to the VAR, where $m$ is the maximum order of integration observed in either series. The coefficients on these extra $m$ lags are not included in the Wald tests, which use only the coefficients of those lags necessary to optimize the information criterion and remove any residual autocorrelation.

\section{Results}

\subsection{Summary Statistics}

Summary statistics for the daily returns to each of the gilts in the sample are contained in Table 2. Allowing for the differences in sample size, the mean returns and the return standard deviations both show the expected positive relation with the maturity of the bond. The skewness and kurtosis of returns indicate departure from a normal distribution, particularly for the excess kurtosis. The kurtosis is greater for the shorter maturity bonds, which at least in part reflects the greater number of zero return days among these bonds. Zero returns are most commonly observed as the bond approaches its maturity date, which suggests that there may still be some residual pull-to-par effects in the data, despite the sample selection attempts to minimize this. The excess kurtosis could also be a symptom of time varying variances, which we shall examine further below.

\footnotetext{
9. Our use of a narrow measure of the money supply represents a conservative approach and avoids endogeneities arising from some of the bonds being counted in the money supply measure.
} 
Table 3 reports the estimated autocorrelation statistics of the daily returns up to lag five. These indicate that there is significant positive first order autocorrelation in almost all of the daily bond returns. For the longer term bonds, there is also significant negative second and third order autocorrelation in the returns. While statistically significant, the autocorrelations detected are rarely beyond 10 percent in absolute value. Steeley and Ahmad (2002) have shown that autocorrelations of this magnitude within individual UK bond returns cannot be exploited for economic profit.

Alongside excess kurtosis, a further indication that returns might exhibit a time varying variance structure is evidenced by significant autocorrelation in the squares or absolute values of the returns. Table 4 contains the associated autocorrelation statistics for squared returns up to lag five. These statistics are considerably larger than those observed for the returns in Table 3, where for first order autocorrelation they reach beyond 40 percent. All the autocorrelation coefficients for all the bonds at all lags up to five are statistically significant at 0.1 percent. This Table provides strong evidence that individual bond returns possess a time varying variance structure.

\subsection{The effects of QE on the volatility of individual gilts}

We use the GARCH model described in Section 2.1 above to estimate the time varying variance structure for each of the individual bonds, also permitting the variance level to change during the phases of QE. The estimated coefficients from this model are displayed in Tables 5 and 6. Table 5 contains the estimated coefficients for the conditional mean equation component of equation (1), while Table 6 contains the estimated coefficients for the conditional volatility equation.

The estimated parameters for the conditional mean equation, in Table 5, indicate that the QE1 phase led to a lowering of the returns of the short and medium term gilts below the level observed prior to the crisis. This is consistent with the existing literature that showed that QE1 led to a lowering of bond yields. ${ }^{10}$ By contrast, the period preceding QE1 and the QE2 and QE3 phases did not lead to significant changes in gilt returns compared to their pre-crisis levels. Mean returns did not seem to respond to announcements made by the MPC, specific announcements relating to aspects of QE, or to issuance activity. However, on days of APF activity, the gilt purchases by the Bank of England act to increase the price (and hence observed return) of all

10. These studies are summarized in Joyce et al (2012) and Martin and Milas (2012) 
gilts on these days, although for the ultra-short term gilts these increases are not statistically significant. These findings are also consistent with the results of prior event studies on the price effects of QE that also found increases in gilt prices on these days. There is little evidence of bond specific purchases effects on returns beyond this general effect, except for some ultra-long term gilts. The results for the bond index are consistent with those found for the individual bonds.

Table 6 contains the estimated parameters for the conditional volatility equation for each bond and the bond index. The estimated parameters on the lagged squared residual and past conditional variance indicate that the variance processes are stable, and imply half-lives of shocks of between 2 to 3 days for the shorter term bonds, and up to 30 days for longer term bonds. Six of the bonds and also the bond index display evidence that news has an asymmetric effect on volatility depending upon whether it is bad news or good news, the latter having a greater impact. The day of the week dummy variables indicate that there are significant differences in volatility across the week. For shorter term bonds, the coefficients imply that volatility is typically higher on a Monday than for the remaining days of the week. For medium to long term bonds, the coefficients imply that volatility on a Monday is typically lower than on a Tuesday and on a Wednesday, and for some bonds also on a Friday. Thursday's volatility is little different to that on a Monday. Some of the explanation for this may come from the patterns of issuance and APF activity that were presented in Figures 3 and 4, where Monday and Wednesday saw peaks in purchase activity, while Wednesday and Friday saw peaks in issuance activity.

We now examine whether volatility was affected by the onset of the financial crisis, the period from the run on the Northern Rock bank until the start of QE1, and each of the individual phases of QE. The period from the Northern Rock run until QE1 appears to have led to a significant rise in the volatility of UK government bonds at most maturities, particularly so for the short to medium term maturity bonds. This is indicated by the positive and significant coefficients on the variable "N-Rock", which takes the value one during the pre-QE1 period and is otherwise zero. This can also be seen visually in Figure 5, which shows examples of the estimated conditional volatility process across the whole sample period for bonds representing the different maturity ranges. For the ultra-short term and short term bonds depicted, there is a 
step change increase in volatility on the day of the run on Northen Rock and, in each case, volatility steadily increases thereafter until the start of QE1. The figures also show that while volatility was around the same level across the maturity spectrum before the financial crisis, the increase in volatility observed between September 2007 and March 2009 was greater for the longer term bonds. For the shorter term bonds, the peak of volatility at the start of QE1 was around double the pre-crisis average, whereas for the medium and longer term bond, the peak levels were between four and six times greater than the pre-crisis levels.

The graphs in Figure 5 also show that the start of the QE process led to a gradual lowering of the volatility from these peak levels. The parameter estimates for the QE1 period in Table 6 show that volatility reduced back to pre-crisis levels during the QE1 period, for most of the ultra-short term and long term bonds. For these bonds, the coefficient on the QE1 dummy variable is not significant, indicating that the volatility on these bonds during the QE1 phase was not significantly different to the level pre-crisis. Since volatility had increased prior to QE1, this means that during QE1 bond volatility - for the ultra-short and long-term bonds reduced back to pre-crisis levels. By contrast, the short term and medium term maturity bonds, while experiencing a drop in volatility, seen in Figure 5, remained at levels of volatility significantly higher than for the pre-crisis levels. For these bonds, the coefficients on both the "N-Rock" indicator variable and the "QE1" indicator variable are significantly different from zero, evidence that in both periods volatility was above the pre-crisis level. From inspection of Figure 5, however, we can see that volatility nonetheless declined during QE1.

In the period between QE1 and QE2, the volatility of gilt returns appears to experience fewer peaks, but towards the end of this period can be seen to increase once more, particularly among medium and longer term gilts. The next two periods of QE, QE2 and QE3, both act to reduce volatility in the gilt market once more. In the case of ultra-short term and short term gilts, this reduction is to levels significantly lower than the pre-crisis average. Some of this reduction could be due to the nearness to maturity. For the medium and longer term bonds the levels of volatility by the end of QE3 are not significantly different from those experienced before the financial crisis. The results for the gilt index also display the pattern of a significant increase in volatility ahead of QE1, and a return to pre-crisis levels by the end of QE1. Overall, these results show that the phases of QE had significant settling effects on the volatility of the gilt-edged 
market, that had risen by as much as 600 percent before the start of QE1. This is consistent with QE operating through a signalling channel.

Our model also examines the impact on volatility of the announcements of the monthly decisions of the MPC, and of specific announcements relating to QE. Except for three ultra-short term gilts, the announcements of the results of the MPC meetings appear to have an amplifying effect on the volatility of the gilts. This suggests that the results of the meetings themselves do not appear to resolve uncertainty in the immediate term, and so gilt volatility spikes up. This could reflect the switch to the use by the MPC of unconventional policy measures during the sample that arose because the scope to use conventional measures - reducing the interest rate was limited. The reduction in volatility observed for the three ultra-short term gilts that are nearing maturity may well be due to a pull-to-par effect, whereby volume focuses on the bonds not about to expire. In section 3.4 below, we also show that the volatility reduction for the ultrashort term gilts could reflect the relatively small amount of their stock that is purchased during phases of QE. Specific announcements relating to QE appear to affect the volatility of only a few of the gilts in the sample and then only marginally significantly. The small impact of these announcements in this data is most likely due to the frequency of observation being too low to capture the effects. QE announcements have been shown to affect average yields using intra-day data, see Joyce and Tong (2012).

While this observation frequency consideration may also impact upon the effects on volatility of the days of the purchase auctions that comprise the activity of QE, rather more clear patterns are observed in these cases. Specifically, the volatility of ultra-short term gilts appears to reduce significantly on days of purchase auctions, whether or not they are being purchased. As they do not seem to respond in addition to their specific purchases, this also may indicate a switch of trading activity away from these soon to mature bonds into longer term bonds. As longer term bonds have greater convexity, the drop in yields caused by QE purchases is likely to have a bigger impact on the prices of longer term bonds making them more attractive relative to very short term bonds. This could explain the drop in volatility of ultra-short term bonds on these days. The short term bonds appear to increase in volatility on APF days in general, but then significantly decrease - to an overall lower level - on days on which they themselves are purchased. In sub-section 3.4, we explain this in terms of the levels of purchase activity and 
excess supply into the auction. Medium and longer term bond return volatility does not seem to respond to days of purchase activity, but this effect may need higher frequency data to be detected. Similarly, the effects on volatility of bond issuance are confined to a small number of bonds. A small number of bonds of across the range of maturities experience significant falls in return volatility on days that they experience a secondary offering. The short term bonds (including the ultra-short term bonds) respond more generally to issuance activity in the market experiencing a significant reduction in volatility on these days.

\subsection{Pre-announcement anticipation in volatility}

Although the graphs in Figure 5 appear to show that volatility rose over the period before QE1, it is possible that this could disguise some short term anticipation of QE announcements that could lead to a drop in volatility slightly ahead of the start of QE. The results of the event study type method that we used to examine this possibility are shown in Table 7 . In the period immediately preceding the announcement by the Bank of England of the establishment of an asset purchase facility (in January 2009, two months before the announcement of QE1), there is evidence that there was an anticipatory reduction in bond volatility. Although only statistically significant when using the 20 day event window, there are greater than 100 percent reductions in bond volatility observed over these pre-announcement periods. It is clear though that, as found with prior event studies of the effects of QE, there is strong dependence of the results on the event window. This is particularly so ahead of the announcement of QE1, where the forty day event window indicates a significant increase in volatility ahead of this announcement. Shorter window lengths indicate a decrease, but not significantly. A similar, window dependent, result is obtained ahead of QE2 where now the 20-day window indicates a significant increase. Ahead of QE3, however, there appears consensus that any near-term anticipation of QE3 raised volatility. So, it is only really the case that volatility dropped in anticipation of the first signs of policy action. By contrast, the rise in volatility ahead of QE3 may reflect a concern that phases of QE were continuing to return and that economic recovery was taking longer than previously anticipated. 


\subsection{The sensitivity of volatility to bond characteristics}

These results in Table 6 have been presented by maturity category, but there are other differences among the bonds that could be explaining the sensitivity of volatility to the phases of $\mathrm{QE}$, announcements and purchase and issuance activity. Table 8 presents the results of cross section regressions that attempt to explain which are the characteristics of a bond that make it more susceptible to changes volatility during the financial crisis and the phases of QE. During the first period of QE, gilts that have both greater time to maturity and higher coupons experience greater effects upon volatility relative to the pre-crisis. Bonds that experience relatively more purchase activity are also likely to experience higher volatility sensitivity during QE1 than was the case beforehand. However, those bonds that holders most wished to sell to the Bank of England, were the ones least likely to experience rises in volatility sensitivity during QE1. In the QE2 period, bonds with longer time to maturity and greater purchase activity are also more likely to experience higher volatility sensitivity than in the pre-crisis period. Furthermore, the more supply available for the Bank to purchase the higher the volatility sensitivity is likely to be during QE2. This effect is also seen during QE3. During the period of time between the run on Northern Rock bank and the start of QE1, increases in volatility are more likely to arise for bonds with greater coupon levels.

Bonds are more likely to experience an increase in volatility on days that they are purchased by the Bank if they are generally experiencing greater relative purchase activity and there is an excess supply into the purchase auction process. However, this excess supply variable has the reverse effect with regards to days when purchase activity is taking place but may not include the bond in question. Taken together, these two features can explain the volatility decline that is seen for short term bonds and that is absent for medium and longer term bonds. Short term bonds are characterized by relatively smaller excess supply, the principal component variable that captures the excess supply effect - described in Section 2.3, typically takes negative values for short term bonds but positive values for medium to longer term bonds. The positive relationship between excess supply and volatility, on days of own-purchase activity, in Table 8 , means that the relatively small excess supply of short term bonds into auctions is reducing the volatility impact of own-purchases. On general APF days, the short term bonds displayed an 
increase in volatility, which is consistent with the relatively small excess supply and the negative relationship between excess supply and volatility found on APF days.

Volatility is more likely to increase on days of the announcements of the decisions of the MPC, if the bond has a longer time to maturity and experiences greater purchase activity. As the two shortest of the ultra-short term bonds experience substantially less purchase activity than most of the other bonds, this could explain the reduction in volatility seen for these two bonds on days of MPC announcements. Most other bonds experienced a rise (not always significant as the usual levels) and this would then be consistent with the greater relative purchase activity for these other issues. The effects on volatility of specific announcements relating to QE do not seem to differ by the characteristics of the bond. The volatility of bonds on days of issuance, either of their own or other issues, is more likely to be higher if they experience relatively less issuance. This indicates that relatively unusual issuance is viewed with caution and the volatility effects may be reflecting significant changes in the liquidity of the bond.

Overall, these results suggest, as expected, that bonds with greater maturity tend to have more volatile response to shocks. The effects of $\mathrm{QE}$ on volatility respond to the purchase activity and the excess supply of stock into the auction process, but these effects change across the QE periods, consistent with the market becoming more adaptable to the purchase activity. The amount of purchase activity is also the key factor in determining how volatility responds to days of purchase auctions and also announcements by the MPC. Volatility is also affected by issuance, and seems to respond more strongly for bonds which see relatively fewer issuance events.

\subsection{Gilt volatility and the money supply}

The results, in Table 9, of the Granger-causality tests between the money supply and gilt volatility present a mixed picture, depending upon the significance level applied and to a lesser extent upon the maturity of the bond. At a one percent level of significance, only four out of the 24 gilts display evidence of causality from the money supply to gilt volatility. At a five percent level, five further gilts display causation from the money supply to gilt volatility. At a 10 percent level, a total of 11 of the gilts display causation from the money supply to gilt volatility. At this level of significance, there are many instances where the null hypothesis of no-causation is 
rejected in both directions. So, overall, with fewer than half of the gilts displaying significant unidirectional causation from the money supply, even at a 10 percent level, it is difficult to conclude that the evolution of the money supply can explain the volatility changes induced by the phases of QE. This further suggests that both the money supply and gilt volatility were responding to the unconventional monetary policy action, but that there was little supplementary causation from the money supply to gilt volatility. However, we note that causation is strongest among short and medium term bonds, where we found earlier (Table 6) that gilt volatility remained relatively high during QE1. This perhaps suggests that the portfolio balance channel of QE was at work with these bonds. Overall, these results suggest that it is most likely that gilt volatility was responding primarily to the signalling channel of $\mathrm{QE}$, whereby $\mathrm{QE}$ is interpreted as a means of calming market turbulence, rather than responding to portfolio rebalancing effects. ${ }^{11}$

\section{Conclusion}

The UK bond market, the gilt-edged market, has been the prime instrument through which the Bank of England, as the UK's monetary authority, has operated its policy of quantitative easing, QE. This has been done with little apparent concern for the welfare of the gilt market itself, since it has been regarded as a robust market place, for example,

"Nor were its (the MPC) actions focussed on improving the functioning of gilt markets where liquidity premia, even in stressed times, were considered to be small." (Joyce et al, 2011)

However, QE is an unconventional monetary policy, and its likely effects on the gilt edged market itself were unknown. This paper has examined one aspect of the possible effects of QE on the gilt-edged market, the effect on volatility.

The onset of the financial crisis that, for the gilt-edged market, appears to date from the run on the Northern Rock bank in September 2007, saw a hugely significant rise in the volatility of individual gilts, across the maturity spectrum. The effects were particularly large among longer term bonds, where a six fold increase from pre-crisis levels was not unusual. Indication that this was potentially causing some liquidity stress in the market is provided by Joyce et al

11. A similar argument has been made by Steeley (2014) in the context of the effects of QE on the gilt yield curve, where it appears that signalling channel effects are more pronounced than portfolio balance effects. 
(2011) who report that average bid-ask spreads increased three-fold in the period between September 2007 and March 2009.

Modelling the conditional volatility of individual gilt returns, using a GARCH model, we find that the onset of QE led to a reduction in this volatility across the maturity spectrum. For ultra-short term bonds and long term bonds, the activity associated with QE1 reduced volatility back to pre-crisis levels. For short and medium term bonds, volatility also reduced but remained at a level significantly above the pre-crisis level, even after the QE1 phase had completed. However, the subsequent rounds of $\mathrm{QE}$, reduced the volatility of all individual bonds further, so that the volatility of all individual gilts was at or below the pre-crisis level. Furthermore, we find some evidence that volatility began to decrease in anticipation of unconventional monetary policy being adopted in the UK.

We used a cross section regression model to identify which bonds were more or less likely to experience volatility changes as a result of the financial crisis and the phases of QE. As would be expected the longer maturity bonds demonstrated a greater volatility sensitivity, but other factors had an influence also. Bonds that experienced the most purchase auction activity were the ones less likely to see significant reductions in volatility during QE. However, this effect was mostly observed during the first phase of QE indicating that the market became more adept at accommodating the purchase activity as the monetary authority interventions continued. Where counterparties offered relatively more for sale than was purchased by the Bank of England, these gilts were more likely to experience a decrease in volatility as a result of QE.

The relative amount of purchase activity that an individual gilt experienced during QE also affected its volatility response on the days of the purchase auction activity, although only a relatively small number of bonds showed any volatility response to these event days. These effects and those of days of bond issuance were primarily confined to shorter term bonds. The response of volatility to a bond having further issuance (a secondary offering) seems to depend on the extent to which such issuance is unusual. Bonds experiencing regular and relatively larger issuance appear to accommodate this activity without affecting volatility. Bonds with infrequent and relatively small issuance seem to experience greater volatility impacts. 
To establish the transmission mechanism through which unconventional monetary policy was affecting gilt volatility, we examined the causal relationship between the money supply and gilt volatility. We found little evidence to indicate that changes in the money supply were causing the observed changes in gilt volatility. This suggests that QE's effects on the volatility in the gilt market were not primarily operating through a portfolio balance channel.

Overall, the effects of QE on bond market volatility are positive. The market appeared to be experiencing unusually high levels of volatility in the immediately preceding two years, and these were reduced across the maturity spectrum by the activities of QE. While short and medium term bonds took three phases of $\mathrm{QE}$ to restore pre-crisis levels of volatility, the secondary market liquidity effects of the purchase auctions that comprise QE have restored the volatility of the gilt-edged market to its pre-crisis state. This volatility reduction induced by QE is, however, consistent with both the signalling and liquidity channels of $\mathrm{QE}$, where enhanced liquidity coupled with a strong monetary easing signal has led to renewed calm in the gilt market.

So, while QE has been operating on the wider financial and economic system through the gilt-edged market it has also had the beneficial side effect of restoring the volatility of the market to pre-crisis levels. This is important because the stated aim of UK debt management policy is:

"to minimise over the long term, the costs of meeting the Government's financing needs, taking into account risk, whilst ensuring that debt management policy is consistent with the aims of monetary policy". (UK Debt Management Office, 2013).

If $\mathrm{QE}$ had left the volatility of the gilt-edged market above pre-crisis levels, then the financial crisis could have had a permanent effect on the cost of debt issuance. By restoring volatility to pre-crisis levels, QE has ensured that this has not been the case. 


\section{References}

Abad, P., and Chulia, H., (2013). European Government Bond Markets and Monetary Policy Surprises: Returns, Volatility and Integration, unpublished working paper, University Rey Juan Carlos, Madrid, Spain.

Ahmad, F., and Steeley, J., (2008). Secondary market pricing behaviour around UK bond auctions, Applied Financial Economics 18, 691-699.

Arnold, I., and Vrugt, E., (2010). Treasury Bond Volatility and Uncertainty about Monetary Policy, The Financial Review 45, 707-728.

Anderson, N., and Breedon, F., (2000). Fifty Years of UK Asset Price Volatility, Journal of Risk 2, 63-77

Balduzzi, P., Elton, E.J., Green, T.C., 2001. Economic news and bond prices: evidence from the U.S. treasury market. Journal of Financial and Quantitative Analysis 36, 523 - 543.

Benford, J., Berry, S., Nikolov, K., and Young, C., (2009). Quantitative easing. Bank of England Quarterly Bulletin, 2009(2), 90-100.

Bollerslev, T. (1986) Generalized Autoregressive Conditional Heteroscedasticity, Journal of Econometrics 31, 307-327.

Bomfim, A., (2003). Pre-announcement effects, news effects, and volatility: Monetary policy and the stock market, Journal of Banking Finance 27, 133-151.

Breedon, F., Chadha, J. S., and Waters, A. (2012), The Financial Market Impact of UK Quantitative Easing, Oxford Review of Economic Policy 28, 702-728.

Breedon, F. and Ganley, J., (2000). Bidding and information: evidence from gilt-edged auctions, The Economic Journal 110, 963-84.

Debt Management Office (DMO), 2013, Gilt Annual Review 2012-2013.

De Goeij, P. and Marquering, W. (2006) Macroeconomic Announcements and Asymmetric Volatility in Bond Returns, Journal of Banking and Finance 30, 2659-2680.

Ederington, L., and Lee, J., (1993). How markets process information: News releases and volatility, Journal of Finance 48, 1161-1191

Engle, R., (1982) Autoregressive conditional heteroscedasticity with estimates of the variance of UK inflation, Econometrica 50, 987-1007.

Engle, R., Lilien, D., and Robins, R., (1987). Estimating Time Varying Risk Premia in the Term Structure: The ARCH-M Model, Econometrica 55, 391-407. 
Glick, R., and Leduc, S. (2012). Central Bank Announcements of Asset Purchases and the Impact on Global Financial and Commodity Markets, Journal of International Money and Finance 31, 2078-2102.

Glosten, L.R., Jagannathan, R., Runkle, D.E. (1993). On the relation between the expected value and the volatility of the nominal excess return on stocks. Journal of Finance 48, 17791801.

Graham, M., Nikkinen, J., and Sahlström, P. (2003). Relative importance of scheduled macroeconomic news for stock market investors, Journal of Economics and Finance 27, $153-165$

Huang, J., and Lu, L., (2008). Macro factors and volatility of Treasury bond returns, unpublished working paper, Penn State University.

Hughes, M., Smith, S., and Winters, D., (2008) The effect of auctions on daily treasury bill volatility, Quarterly Review of Economics and Finance 48, 48-60.

Johnson, R. and Young, P. (2002) Bond Market Volatility Compared with Stock Market Volatility: evidence from the UK, Journal of Asset Management 3, 101-111

Jones, C., Lamont, O., and Lumsdaine, R., (1998). Macroeconomic news and bond market volatility, Journal of Financial Economics 47, 315-337.

Joyce, M., Lasaosa, A., Stevens, I., and Tong, M. (2011), The Financial Market Impact of Quantitative Easing in the United Kingdom, International Journal of Central Banking, 7, 113-61.

Joyce, M., McLaren, N., and Young, C., (2012), Quantitative easing in the United Kingdom: evidence from financial markets on QE1 and QE2, Oxford Review of Economic Policy $28,671-701$.

Joyce, M., and Tong, M. (2012), QE and the Gilt Market: A Disaggregated Analysis, Economic Journal 122, F348-84.

Kearney, A., and Lombra, R., (2004). Stock market volatility, the news, and monetary policy Journal of Economics and Finance 28, pp. 252-259

Lucca, D., and Moench, E., (2011),The pre-FOMC announcement drift, Staff Report, Federal Reserve Bank of New York, No. 512

Martin, C., and Milas, C., (2012), Quantitative Easing: A skeptical survey, Oxford Review of Economic Policy 28, 750-764. 
Meier, A. (2009), Panacea, Curse, or Nonevent: Unconventional Monetary Policy in the United Kingdom, IMF Working Paper No. 09/163.

Meaning, J., and Zhu, F. (2011), The Impact of Recent Central Bank Asset Purchase Programmes, Bank of International Settlements Quarterly Review, December, 73-83.

Nelson, D., (1991) Conditional Heteroskedasticity in Asset Returns: A New Approach, Econometrica 59, pp.347-70.

Nikkinen, J., and Sahlström, P. (2001). Impact of Scheduled U.S. Macroeconomic News on Stock Market Uncertainty: A Multinational Perspecive. Multinational Finance Journal 5, 129-139.

Nikkinen, J., and Sahlström, P., (2004a). Impact of the federal open market committee's meetings and scheduled macroeconomic news on stock market uncertainty, International Review of Financial Analysis 13, 1-12.

Nikkinen, J., and Sahlström, P., (2004b). Scheduled domestic and US macroeconomic news and stock valuation in Europe, Journal of Multinational Financial Management 14, 201-215.

Nikkinen, J., Omran, M., Sahlstrom, P., and Aijo, J., (2006). Global stock market reactions to scheduled U.S. macroeconomic news announcements, Global Finance Journal 17, 92104.

Nowak, S., Andritzky, J., Jobst, A. and Tamirisa, N., (2011). Macroeconomic fundamentals, price discovery, and volatility dynamics in emerging bond markets. Journal of Banking \& Finance 35, 2584-2597.

Ross, S., (1989). Information and Volatility: The No-Arbitrage Martingale Approach to Timing and Resolution Irrelevancy, The Journal of Finance 44, 1-17.

Steeley, J., (1992). Deregulation and market efficiency: Evidence from the gilt-edged market, Applied Financial Economics 2, 125-143.

Steeley, J., and F. Ahmad, (2002). The effects of safe-haven status on the gilt-edged market, Journal of Bond Trading and Management 2, 120-148.

Steeley, J., (2014). Yield curve dimensionality when short rates are near the zero lower bound, in in Developments in Macro-Finance Yield Curve Modelling, Ed. Chadha, J., A. Durre, M.Joyce and L. Sarno, Cambridge University Press, Cambridge.

Tan, J. and Kohli, V. (2011). The Effect of Fed's Quantitative Easing on Stock Volatility, unpublished manuscript, University of California, Berkeley, available from SSRN.

Taylor, S., (1986). Modelling Financial Time Series, Wiley. 
Taylor, S., and Kingsman, B., (1979). An analysis of the variance and distribution of commodity price-changes, Australian Journal of Management 4, 135-149.

Toda, H. and Yamamoto, T., (1995). Statistical inferences in vector autoregressions with possibly integrated processes. Journal of Econometrics 66, 225-250.

Veronesi, P., (1999). Stock market overreaction to bad news in good times: a rational expectations equilibrium model, Review of Financial Studies 12, 975 - 1007.

Won, S., Yun, Y.S., and Kim, B.J. (2013) Emerging Bond Market Volatility and Country Spreads, Emerging Markets Finance \& Trade 49, 82-100. 
Table 1: Key QE Announcements relating to UK government bonds

\begin{tabular}{|c|c|c|}
\hline $\begin{array}{l}\text { Announcement } \\
\text { date }\end{array}$ & Decision on QE & Other decisions \\
\hline 19 January 2009 & $\begin{array}{l}\text { The Chancellor of the Exchequer announces that the } \\
\text { Bank of England will set up an asset purchase } \\
\text { programme }\end{array}$ & \\
\hline 30 January 2009 & $\begin{array}{l}\text { Asset Purchase Facility Fund established. Exchange of } \\
\text { letters between the Chancellor of the Exchequer and } \\
\text { the Governor on } 29 \text { January } 2009 \text {. }\end{array}$ & \\
\hline 11 February 2009 & $\begin{array}{l}\text { Bank of England's February Inflation Report and the } \\
\text { associated press conference give strong indication that } \\
\text { QE asset purchases are likely. }\end{array}$ & \\
\hline 5 March 2009 & $\begin{array}{l}\text { The MPC announces it will purchase } £ 75 \text { billion of } \\
\text { assets over three months funded by central bank } \\
\text { money. Conventional bonds likely to constitute the } \\
\text { majority of purchases, restricted to bonds with residual } \\
\text { maturity between } 5 \text { and } 25 \text { years. }\end{array}$ & $\begin{array}{l}\text { Base rate reduced from } 1 \% \text { to } \\
0.5 \% \text {. }\end{array}$ \\
\hline 11 March 2009 & First purchases of UK government bonds (gilts). & \\
\hline 7 May 2009 & $\begin{array}{l}\text { The MPC announces that the amount of QE asset } \\
\text { purchases will be extended by a further } £ 50 \text { billion to } \\
£ 125 \text { billion. }\end{array}$ & \\
\hline 6 August 2009 & $\begin{array}{l}\text { The MPC announces that QE asset purchases will be } \\
\text { extended to } £ 175 \text { billion and that the buying range will } \\
\text { be extended to gilts with a residual maturity greater } \\
\text { than three years, and split between maturity ranges: } 3 \text { - } \\
10 \text { years, } 10 \text { to } 25 \text { years, and more than } 25 \text { years. }\end{array}$ & $\begin{array}{l}\text { The Bank announces a gilt } \\
\text { lending programme, which } \\
\text { allows counterparties to borrow } \\
\text { gilts from the APF's portfolio } \\
\text { via the DMO in return for a fee } \\
\text { and alternative gilts as } \\
\text { collateral. }\end{array}$ \\
\hline 5 November 2009 & $\begin{array}{l}\text { The MPC announced that the amount of QE asset } \\
\text { purchases would be extended to } £ 200 \text { billion. }\end{array}$ & \\
\hline 4 February 2010 & $\begin{array}{l}\text { The MPC announced that the amount of QE asset } \\
\text { purchases would be maintained at } £ 200 \text { billion. }\end{array}$ & $\begin{array}{l}\text { The MPC's press statement } \\
\text { said that the committee would } \\
\text { continue to monitor the } \\
\text { appropriate scale of the asset } \\
\text { purchase programme and that } \\
\text { further purchases would be } \\
\text { made should the outlook } \\
\text { warrant them. }\end{array}$ \\
\hline 6 October 2011 & $\begin{array}{l}\text { The MPC announces that the amount of QE asset } \\
\text { purchases will be extended by } £ 75 \text { billion to } £ 275 \\
\text { billion. The start of QE2. }\end{array}$ & \\
\hline 9 February 2012 & $\begin{array}{l}\text { The MPC announces that the amount of QE asset } \\
\text { purchases will be extended by a further } £ 50 \text { billion to } \\
£ 325 \text { billion. }\end{array}$ & $\begin{array}{l}\text { The maturity range boundaries } \\
\text { are changed from } 10 \text { and } 25 \\
\text { years to } 7 \text { and } 15 \text { years. }\end{array}$ \\
\hline 5 July 2012 & $\begin{array}{l}\text { The MPC announces that the amount of QE asset } \\
\text { purchases will be extended by } £ 50 \text { billion to } £ 375 \\
\text { billion. The start of QE3. }\end{array}$ & \\
\hline
\end{tabular}

Source: Joyce at al (2011) and Joyce et al (2012). 
Table 2: Summary Statistics

\begin{tabular}{|c|c|c|c|c|c|c|c|c|c|c|c|}
\hline Bond Name & No. Obs. & Mean & Std. Dev. & Minimum & Quartile 1 & Median & Quartile 3 & Maximum & Skewness & Kurtosis & Zeros \\
\hline TRSY $4.5 \% 2013$ & 1264 & -0.00001 & 0.00187 & -0.01142 & -0.00048 & -0.00010 & 0.00056 & 0.01137 & -0.093 & $7.409 * * *$ & 83 \\
\hline TRSY $8 \% 2013$ & 2362 & $-0.00008 *$ & 0.00202 & -0.01045 & -0.00097 & -0.00018 & 0.00089 & 0.01157 & 0.027 & $3.266^{* * *}$ & 56 \\
\hline TRSY 5\% 2014 & 2362 & 0.00002 & 0.00245 & -0.01134 & -0.00116 & 0.00000 & 0.00136 & 0.01106 & -0.035 & $2.369 * * *$ & 72 \\
\hline TRSY 4.75\% 2015 & 2362 & 0.00005 & 0.00281 & -0.01229 & -0.00149 & 0.00000 & 0.00159 & 0.01665 & -0.008 & $2.509 * * *$ & 40 \\
\hline TRSY $8 \% 2015$ & 2362 & -0.00003 & 0.00270 & -0.01205 & -0.00150 & -0.00008 & 0.00148 & 0.01857 & $0.085^{*}$ & $2.983 * * *$ & 36 \\
\hline TRSY 4\% 2016 & 1820 & 0.00007 & 0.00321 & -0.01376 & -0.00167 & 0.00000 & 0.00179 & 0.02022 & $0.119 * *$ & $3.199 * * *$ & 27 \\
\hline TRSY 8.75\% 2017 & 2362 & -0.00001 & 0.00322 & -0.01630 & -0.00184 & -0.00007 & 0.00187 & 0.02317 & $0.111^{* *}$ & $2.996 * * *$ & 22 \\
\hline TRSY 5\% 2018 & 1505 & 0.00013 & 0.00388 & -0.01865 & -0.00193 & 0.00009 & 0.00239 & 0.02317 & 0.060 & $2.768^{* * *}$ & 23 \\
\hline TRSY4.5\% 2019 & 1165 & 0.00016 & 0.00420 & -0.01927 & -0.00223 & 0.00009 & 0.00258 & 0.02468 & $0.232^{* * *}$ & $2.967^{* * *}$ & 22 \\
\hline TRSY $4.75 \% 2020$ & 2055 & 0.00010 & 0.00420 & -0.01952 & -0.00243 & 0.00010 & 0.00275 & 0.02385 & 0.049 & $1.695^{* * *}$ & 13 \\
\hline TRSY $8 \% 2021$ & 2362 & 0.00004 & 0.00410 & -0.01934 & -0.00241 & 0.00007 & 0.00263 & 0.02346 & 0.042 & $1.663^{* * *}$ & 17 \\
\hline TRSY $4 \% 2022$ & 1065 & 0.00015 & 0.00497 & -0.02324 & -0.00306 & 0.00019 & 0.00322 & 0.02570 & 0.100 & $1.788^{* * *}$ & 13 \\
\hline TRSY $5 \% 2025$ & 2362 & 0.00010 & 0.00526 & -0.02649 & -0.00294 & 0.00018 & 0.00334 & 0.05156 & $0.483^{* * *}$ & $6.778^{* * *}$ & 18 \\
\hline TRSY $4.25 \% 2027$ & 1686 & 0.00012 & 0.00641 & -0.03082 & -0.00350 & 0.00000 & 0.00394 & 0.06228 & $0.639 * * *$ & $8.077^{* * *}$ & 23 \\
\hline TRSY $6 \% 2028$ & 2362 & 0.00009 & 0.00575 & -0.02990 & -0.00309 & 0.00017 & 0.00358 & 0.05836 & $0.493^{* * *}$ & $7.227^{* * *}$ & 24 \\
\hline TRSY 4.75\% 2030 & 1414 & 0.00018 & 0.00716 & -0.03210 & -0.00388 & 0.00019 & 0.00447 & 0.06312 & $0.499 * * *$ & $6.434^{* * *}$ & 16 \\
\hline TRSY $4.25 \% 2032$ & 2362 & 0.00011 & 0.00663 & -0.03401 & -0.00365 & 0.00020 & 0.00410 & 0.06691 & $0.438^{* * *}$ & $6.734^{* * *}$ & 24 \\
\hline TRSY 4.25\% 2036 & 2362 & 0.00011 & 0.00702 & -0.03621 & -0.00398 & 0.00020 & 0.00433 & 0.05472 & $0.126^{* *}$ & $3.365 * * *$ & 18 \\
\hline TRSY 4.75\% 2038 & 2293 & 0.00011 & 0.00720 & -0.03474 & -0.00414 & 0.00019 & 0.00440 & 0.05074 & 0.068 & $2.698 * * *$ & 17 \\
\hline TRSY 4.25\% 2039 & 1054 & 0.00019 & 0.00800 & -0.03011 & -0.00473 & 0.00005 & 0.00487 & 0.04848 & $0.216^{* * *}$ & $1.743 * * *$ & 2 \\
\hline TRSY $4.25 \% 2042$ & 1498 & 0.00016 & 0.00861 & -0.03399 & -0.00500 & 0.00010 & 0.00528 & 0.05147 & 0.036 & $1.885^{* * *}$ & 12 \\
\hline TRSY 4.25\% 2046 & 1767 & 0.00010 & 0.00876 & -0.03608 & -0.00512 & 0.00000 & 0.00515 & 0.05485 & 0.066 & $2.072^{* * *}$ & 15 \\
\hline TRSY $4.25 \% 2049$ & 1182 & 0.00018 & 0.01006 & -0.03682 & -0.00589 & 0.00000 & 0.00596 & 0.05564 & 0.066 & $1.626^{* * *}$ & 8 \\
\hline TRSY $4.25 \% 2055$ & 2009 & 0.00010 & 0.00934 & -0.03947 & -0.00539 & 0.00009 & 0.00544 & 0.05784 & 0.066 & $2.091^{* * *}$ & 6 \\
\hline Gilt Index & 2362 & 0.00011 & 0.00696 & -0.03285 & -0.00384 & 0.00022 & 0.00421 & 0.05678 & $0.115^{* *}$ & $2.819 * * *$ & 5 \\
\hline
\end{tabular}


Table 3: Autocorrelation statistics for returns

\begin{tabular}{|c|c|c|c|c|c|c|c|c|c|c|}
\hline Bond Name & $A C(1)$ & $\mathrm{AC}(2)$ & $\mathrm{AC}(3)$ & $\mathrm{AC}(4)$ & $A C(5)$ & $Q(1) p$ & $Q(2) p$ & $Q(3) p$ & $\mathrm{Q} 4(\mathrm{p})$ & Q5(p) \\
\hline TRSY 4.5\% 2013 & 0.0552 & 0.0100 & -0.0089 & -0.0029 & -0.0491 & 0.049 & 0.136 & 0.252 & 0.392 & 0.208 \\
\hline TRSY 8\% 2013 & 0.0490 & -0.0128 & -0.0067 & 0.0229 & -0.0187 & 0.017 & 0.048 & 0.103 & 0.115 & 0.143 \\
\hline TRSY 5\% 2014 & 0.0371 & -0.0281 & -0.0046 & 0.0331 & -0.0236 & 0.072 & 0.077 & 0.160 & 0.101 & 0.106 \\
\hline TRSY $4.75 \% 2015$ & 0.0442 & -0.0302 & -0.0104 & 0.0375 & -0.0202 & 0.031 & 0.034 & 0.071 & 0.035 & 0.045 \\
\hline TRSY 8\% 2015 & 0.0484 & -0.0273 & -0.0054 & 0.0422 & -0.0178 & 0.019 & 0.026 & 0.061 & 0.021 & 0.031 \\
\hline TRSY 4\% 2016 & 0.0384 & -0.0162 & 0.0001 & 0.0492 & -0.0215 & 0.101 & 0.205 & 0.366 & 0.108 & 0.134 \\
\hline TRSY $8.75 \% 2017$ & 0.0500 & -0.0456 & -0.0126 & 0.0448 & -0.0109 & 0.015 & 0.004 & 0.011 & 0.003 & 0.006 \\
\hline TRSY 5\% 2018 & 0.0507 & -0.0406 & -0.0165 & 0.0469 & -0.0193 & 0.049 & 0.041 & 0.079 & 0.039 & 0.058 \\
\hline TRSY4.5\% 2019 & 0.0746 & -0.0718 & -0.0053 & 0.0621 & -0.0139 & 0.011 & 0.002 & 0.006 & 0.002 & 0.004 \\
\hline TRSY $4.75 \% 2020$ & 0.0359 & -0.0416 & -0.0355 & 0.0449 & -0.0071 & 0.103 & 0.045 & 0.032 & 0.011 & 0.023 \\
\hline TRSY 8\% 2021 & 0.0346 & -0.0502 & -0.0358 & 0.0439 & -0.0076 & 0.092 & 0.012 & 0.008 & 0.003 & 0.005 \\
\hline TRSY $4 \% 2022$ & 0.0287 & -0.0996 & 57 & 0.0484 & -0.01 & 0.348 & 0.003 & 0.003 & 0.003 & 0.005 \\
\hline TRSY 5\% 2025 & 0.0567 & -0.0705 & -0.0523 & 0.0534 & 0.0044 & 0.006 & 0.000 & 0.000 & 0.000 & 0.000 \\
\hline TRSY $4.25 \% 2027$ & 0.0743 & -0.0752 & -0.0592 & 0.0632 & 0.0087 & 0.002 & 0.000 & 0.000 & 0.000 & 0.000 \\
\hline TRSY 6\% 2028 & 0.0588 & -0.0698 & -0.0619 & 0.0545 & 0.0155 & 0.004 & 0.000 & 0.000 & 0.000 & 0.000 \\
\hline TRSY $4.75 \% 2030$ & 0.0751 & -0.0908 & -0.0691 & 0.0680 & 0.0123 & 0.005 & 0.000 & 0.000 & 0.000 & 0.000 \\
\hline TRSY $4.25 \% 2032$ & 0.0647 & -0.0864 & -0.0683 & 0.0581 & 0.0115 & 0.002 & 0.000 & 0.000 & 0.000 & 0.000 \\
\hline TRSY $4.25 \% 2036$ & 0.0590 & -0.0889 & -0.0825 & 0.0522 & 0.0054 & 0.004 & 0.000 & 0.000 & 0.000 & 0.000 \\
\hline TRSY $4.75 \% 2038$ & 0.0579 & -0.0949 & -0.0933 & 0.0553 & 0.0028 & 0.005 & 0.000 & 0.000 & 0.000 & 0.000 \\
\hline TRSY $4.25 \% 2039$ & 0.0291 & -0.1168 & -0.1149 & 0.0563 & 0.0130 & 0.345 & 0.000 & 0.000 & 0.000 & 0.000 \\
\hline TRSY $4.25 \% 2042$ & 0.0628 & -0.1041 & -0.1034 & 0.0606 & -0.0012 & 0.015 & 0.000 & 0.000 & 0.000 & 0.000 \\
\hline TRSY $4.25 \% 2046$ & 0.0527 & -0.0938 & -0.1060 & 0.0532 & -0.0036 & 0.027 & 0.000 & 0.000 & 0.000 & 0.000 \\
\hline TRSY $4.25 \% 2049$ & 0.0882 & -0.1281 & -0.1106 & 0.0712 & 0.0032 & 0.002 & 0.000 & 0.000 & 0.000 & 0.000 \\
\hline TRSY $4.25 \% 2055$ & 0.0621 & -0.1040 & -0.1141 & 0.0545 & -0.0035 & 0.005 & 0.000 & 0.000 & 0.000 & 0.000 \\
\hline Gilt Index & 0.0523 & -0.0993 & -0.0828 & 0.0431 & 0.0094 & 0.011 & 0.000 & 0.000 & 0.000 & 0.000 \\
\hline
\end{tabular}


Table 4: Autocorrelation statistics for squared returns

\begin{tabular}{|c|c|c|c|c|c|c|c|c|c|c|}
\hline Bond Name & $\mathrm{AC}(1)$ & $\mathrm{AC}(2)$ & $A C(3)$ & $A C(4)$ & $A C(5)$ & Q1 & Q2 & Q3 & Q4 & Q5 \\
\hline TRSY 4.5\% 2013 & 0.1780 & 0.2030 & 0.1835 & 0.2113 & 0.2949 & 40.15 & 92.38 & 135.14 & 191.84 & 302.37 \\
\hline TRSY 8\% 2013 & 0.1224 & 0.1195 & 0.1230 & 0.1607 & 0.2477 & 35.45 & 69.21 & 105.04 & 166.19 & 311.50 \\
\hline TRSY 5\% 2014 & 0.1530 & 0.0851 & 0.1009 & 0.1476 & 0.1954 & 55.35 & 72.50 & 96.58 & 148.18 & 238.64 \\
\hline TRSY $4.75 \% 2015$ & 0.1940 & 0.0566 & 0.0689 & 0.1129 & 0.1880 & 89.01 & 96.60 & 107.85 & 138.02 & 221.75 \\
\hline TRSY 8\% 2015 & 0.2331 & 0.0475 & 0.0672 & 0.1022 & 0.1737 & 128.50 & 133.84 & 144.53 & 169.26 & 240.78 \\
\hline TRSY 4\% 2016 & 0.2670 & 0.0623 & 0.0617 & 0.1152 & 0.2197 & 129.97 & 137.04 & 143.98 & 168.19 & 256.41 \\
\hline TRSY 8.75\% 2017 & 0.2462 & 0.0473 & 0.0535 & 0.0968 & 0.1608 & 143.32 & 148.61 & 155.38 & 177.56 & 238.80 \\
\hline TRSY 5\% 2018 & 0.2628 & 0.0489 & 0.0403 & 0.0967 & 0.1979 & 104.13 & 107.74 & 110.19 & 124.32 & 183.54 \\
\hline TRSY4.5\% 2019 & 0.2637 & 0.0472 & 0.0301 & 0.0918 & 0.1859 & 81.23 & 83.84 & 84.90 & 94.77 & 135.25 \\
\hline TRSY 4.75\% 2020 & 0.2160 & 0.0380 & 0.0420 & 776 & 527 & 96.03 & 99.01 & 102.65 & 115.06 & 163.16 \\
\hline TRSY 8\% 2021 & 0.2058 & 0.0408 & 0.0485 & 0.0683 & 0.1378 & 100.19 & 104.13 & 109.69 & 120.75 & 165.71 \\
\hline TRSY 4\% 2022 & 0.2229 & 0.0286 & 0.0381 & 464 & 0.0904 & 53.05 & 53.92 & 55.47 & 57.78 & 66.55 \\
\hline TRSY 5\% 2025 & 0.4201 & 0.0767 & 0.0322 & 0.0897 & 0.1028 & 417.47 & 431.38 & 433.83 & 452.89 & 477.92 \\
\hline TRSY $4.25 \% 2027$ & 0.4181 & 0.0740 & 0.0261 & 0.1010 & 0.0993 & 295.28 & 304.53 & 305.68 & 322.95 & 339.64 \\
\hline TRSY 6\% 2028 & 0.4024 & 0.0835 & 0.0342 & 0.1058 & 0.1049 & 382.98 & 399.47 & 402.24 & 428.74 & 454.82 \\
\hline TRSY $4.75 \% 2030$ & 0.4119 & 0.0853 & 0.0289 & 0.0868 & 0.0877 & 240.44 & 250.76 & 251.95 & 262.64 & 273.57 \\
\hline TRSY $4.25 \% 2032$ & 0.3946 & 0.1042 & 0.0481 & 0.1047 & 0.0965 & 368.24 & 393.91 & 399.38 & 425.36 & 447.40 \\
\hline TRSY 4.25\% 2036 & 0.3485 & 0.1385 & 0.0938 & 0.1151 & 0.1215 & 287.24 & 332.61 & 353.45 & 384.82 & 419.78 \\
\hline TRSY $4.75 \% 2038$ & 0.3224 & 0.1517 & 0.1197 & 0.1307 & 0.1361 & 238.70 & 291.57 & 324.51 & 363.76 & 406.35 \\
\hline TRSY $4.25 \% 2039$ & 0.1268 & 0.0479 & 0.0710 & 0.0789 & 0.0215 & 17.01 & 19.43 & 24.76 & 31.36 & 31.85 \\
\hline TRSY $4.25 \% 2042$ & 0.2948 & 0.1505 & 0.1181 & 0.1301 & 0.1290 & 130.43 & 164.46 & 185.43 & 210.90 & 235.93 \\
\hline TRSY 4.25\% 2046 & 0.2967 & 0.1662 & 0.1371 & 0.1457 & 0.1360 & 155.76 & 204.70 & 238.00 & 275.65 & 308.44 \\
\hline TRSY $4.25 \% 2049$ & 0.2736 & 0.1403 & 0.1146 & 0.1268 & 0.1171 & 88.73 & 112.07 & 127.66 & 146.77 & 163.07 \\
\hline TRSY $4.25 \% 2055$ & 0.2820 & 0.1764 & 0.1523 & 0.1726 & 0.1383 & 160.01 & 222.65 & 269.36 & 329.43 & 367.97 \\
\hline Gilt Index & 0.3328 & 0.1288 & 0.0877 & 0.1306 & 0.1291 & 261.98 & 301.26 & 319.48 & 359.88 & 399.37 \\
\hline
\end{tabular}


Table 5: Estimated parameters on the bond market event indicators in the mean return equation

This table contains maximum likelihood estimates of the parameters, $\gamma_{i}, i=1,2, \ldots, 14$, from the conditional mean equation of the following model applied to the daily returns of gilts, $r_{t}$, using the samples indicated in Table 2.

$$
\begin{gathered}
r_{t}=c+\phi r_{t-1}+\sum_{i=1}^{14} \gamma_{i} D_{i, t}+\varepsilon_{t}-\theta \varepsilon_{t-1} \\
\varepsilon_{t} \mid r_{t-1}, r_{t-2}, \ldots \sim N\left(0, h_{t}\right) \\
h_{t}=\omega+\alpha \varepsilon_{t-1}^{2}+\beta h_{t-1}+\lambda I_{t} \varepsilon_{t-1}^{2}+\sum_{i=1}^{14} \kappa_{i} D_{i, t}
\end{gathered}
$$

The set of dummy variables, $D_{i, t}$, entering both the conditional mean and conditional variance specifications, are indicators of the effects of the three separate phases of QE (QE1, QE2, QE3), the period of time between the run on Northern Rock and the start of QE1 (N-Rock), days of announcements relating specifically to QE (QE Ann), days of announcements of the decision of MPC meetings, days on which the bond was issued (Own Issue) or purchased by the Bank of England through the QE Asset Purchase Facility (Own Purchase), days that any bond was issued (Issue) and days that any bond was purchased by the Bank of England through the QE Asset Purchase Facility (APF), or of other differences related to days of the week (Tues, Wed, Thur, Fri). The reported

\begin{tabular}{|c|c|c|c|c|c|c|c|c|c|c|c|c|c|c|}
\hline & Own Issue & Own Purchase & $\begin{array}{l}\text { Issue } \\
\end{array}$ & APF & QEAnn & MPC & N-Rock & QE1 & QE2 & QE3 & TUES & WED & THUR & $\mathrm{FRI}$ \\
\hline \multicolumn{15}{|c|}{ Ultra-Short-term Gilts } \\
\hline \multirow[t]{2}{*}{ TRSY 4.5\% 2013} & 0.379 & -0.610 & 0.140 & 0.155 & 0.399 & 0.117 & 0.340 & -0.093 & -0.195 & -0.176 & 0.0676 & 0.1080 & 0.0126 & -0.1750 \\
\hline & $(0.64)$ & $(-1.41)$ & $(0.69)$ & $(0.51)$ & $(0.64)$ & $(0.35)$ & $(1.18)$ & $(-0.32)$ & $(-0.49)$ & $(-0.20)$ & $(0.21)$ & $(0.33)$ & $(0.04)$ & $(-0.53)$ \\
\hline \multirow[t]{2}{*}{ TRSY 8\% 2013} & 0.924 & -0.502 & 0.198 & 0.332 & 0.901 & 0.322 & 0.296 & -0.210 & -0.349 & -0.328 & 0.100 & 0.045 & 0.015 & -0.073 \\
\hline & $(1.59)$ & $(-0.93)$ & $(1.14)$ & $(1.07)$ & $(1.41)$ & $(1.27)$ & $(1.61)$ & $(-0.95)$ & $(-1.33)$ & $(-0.67)$ & $(0.41)$ & $(0.18)$ & $(0.06)$ & $(-0.30)$ \\
\hline \multirow{2}{*}{ TRSY 5\% 2014} & 0.214 & 0.183 & 0.198 & 0.259 & 0.792 & 0.435 & 0.360 & -0.411 & -0.346 & -0.308 & -0.022 & -0.112 & -0.139 & 0.052 \\
\hline & $(0.29)$ & $(0.22)$ & $(0.94)$ & $(0.80)$ & $(0.97)$ & $(1.37)$ & (1.59) & $(-1.58)$ & $(-1.11)$ & $(-0.77)$ & $(-0.07)$ & $(-0.38)$ & $(-0.45)$ & $(0.18)$ \\
\hline \multirow[t]{2}{*}{ TRSY $4.75 \% 2015$} & 0.219 & -0.473 & 0.210 & 0.493 & 1.408 & 0.414 & 0.376 & -0.448 & -0.364 & -0.392 & -0.101 & -0.193 & -0.163 & 0.059 \\
\hline & $(0.40)$ & $(-1.19)$ & $(1.03)$ & $(1.60)$ & $(1.44)$ & (1.17) & (1.48) & $(-1.49)$ & $(-1.46)$ & $(-1.23)$ & $(-0.33)$ & $(-0.66)$ & $(-0.50)$ & $(0.19)$ \\
\hline \multirow{2}{*}{ TRSY 8\% 2015} & 0.274 & -0.015 & 0.150 & 0.159 & 1.024 & 0.132 & 0.345 & -0.308 & -0.096 & -0.161 & -0.075 & -0.092 & -0.087 & -0.179 \\
\hline & $(0.58)$ & $(-0.05)$ & (1.16) & $(1.17)$ & $(1.12)$ & $(0.57)$ & $(1.52)$ & $(-1.32)$ & $(-0.66)$ & $(-1.59)$ & $(-0.58)$ & $(-0.67)$ & $(-0.59)$ & $(-1.22)$ \\
\hline \multicolumn{15}{|c|}{ Short-term Gilts } \\
\hline \multirow[t]{2}{*}{ TRSY 4\% 2016} & -1.438 & -0.380 & 0.366 & 0.711 & 2.452 & 0.095 & 0.388 & -0.635 & -0.346 & -0.277 & -0.250 & -0.327 & -0.238 & -0.094 \\
\hline & $(-2.25)$ & $(-0.82)$ & (1.29) & $(1.68)$ & $(2.75)$ & $(0.22)$ & (1.27) & $(-1.81)$ & $(-0.96)$ & $(-0.60)$ & $(-0.62)$ & $(-0.86)$ & $(-0.55)$ & $(-0.22)$ \\
\hline \multirow{2}{*}{ TRSY $8.75 \% 2017$} & 0.504 & -0.169 & 0.126 & 0.536 & 1.425 & 0.283 & 0.326 & -0.567 & -0.306 & -0.169 & -0.185 & -0.271 & -0.308 & -0.155 \\
\hline & $(0.62)$ & $(-0.34)$ & $(0.70)$ & (2.09) & $(1.03)$ & (0.94) & (1.25) & $(-1.84)$ & $(-1.22)$ & $(-1.06)$ & $(-0.67)$ & $(-0.99)$ & $(-1.08)$ & $(-0.56)$ \\
\hline \multirow[t]{2}{*}{ TRSY 5\% 2018} & 0.753 & -0.318 & -0.064 & 0.560 & 1.876 & -0.448 & 0.122 & -0.577 & -0.384 & -0.321 & -0.494 & -0.479 & -0.394 & -0.260 \\
\hline & $(0.67)$ & $(-0.78)$ & $(-0.27)$ & $(2.00)$ & $(1.63)$ & $(-1.42)$ & $(0.42)$ & $(-1.77)$ & $(-1.38)$ & $(-1.74)$ & $(-1.71)$ & $(-1.71)$ & $(-1.44)$ & $(-0.87)$ \\
\hline \multirow{2}{*}{ TRSY4.5\% 2019} & 1.626 & -0.327 & -0.195 & 0.961 & 1.078 & -0.351 & 0.815 & -0.990 & -0.568 & -0.413 & -0.670 & -0.638 & -0.543 & -0.209 \\
\hline & $(0.99)$ & $(-0.49)$ & $(-0.70)$ & $(2.46)$ & $(0.62)$ & $(-0.66)$ & $\begin{array}{l}(1.11) \\
\end{array}$ & $(-2.46)$ & $(-1.51)$ & $\begin{array}{l}(-1.63) \\
\end{array}$ & $(-1.31)$ & $(-1.24)$ & $(-1.00)$ & $(-0.39)$ \\
\hline \multirow{2}{*}{ TRSY $4.75 \% 2020$} & 0.221 & 0.583 & 0.132 & 0.758 & 1.576 & 0.183 & 0.192 & -0.786 & -0.461 & -0.404 & -0.365 & -0.392 & -0.370 & -0.102 \\
\hline & $(0.26)$ & $(1.05)$ & $(0.47)$ & $(2.23)$ & $(0.82)$ & $(0.37)$ & $(0.61)$ & $(-2.10)$ & $(-1.24)$ & $(-1.65)$ & $(-1.49)$ & $(-1.51)$ & $(-1.32)$ & $(-0.39)$ \\
\hline
\end{tabular}
estimates of the parameters $\gamma_{i}, i=1,2, \ldots, 14$, have all been multiplied by $10^{3}$. Below the parameter estimates are robust t-statistics in parentheses. The table is divided into the official maturity classifications at the end of the sample. 
Table 5 cont.: Estimated parameters on the bond market event indicators in the mean return equation

This table contains maximum likelihood estimates of the parameters, $\gamma_{i}, i=1,2, \ldots, 14$, from the conditional mean equation of the following model applied to the daily returns of gilts, $r_{t}$, using the samples indicated in Table 2.

$$
\begin{gathered}
r_{t}=c+\phi r_{t-1}+\sum_{i=1}^{14} \gamma_{i} D_{i, t}+\varepsilon_{t}-\theta \varepsilon_{t-1} \\
\varepsilon_{t} \mid r_{t-1}, r_{t-2}, \ldots \sim N\left(0, h_{t}\right) \\
h_{t}=\omega+\alpha \varepsilon_{t-1}^{2}+\beta h_{t-1}+\lambda I_{t} \varepsilon_{t-1}^{2}+\sum_{i=1}^{14} \kappa_{i} D_{i, t}
\end{gathered}
$$

The set of dummy variables, $D_{i, t}$, entering both the conditional mean and conditional variance specifications, are indicators of the effects of the three separate phases of QE (QE1, QE2, QE3), the period of time between the run on Northern Rock and the start of QE1 (N-Rock), days of announcements relating specifically to QE (QE Ann), days of announcements of the decision of MPC meetings, days on which the bond was issued (Own Issue) or purchased by the Bank of England through the QE Asset Purchase Facility (Own Purchase), days that any bond was issued (Issue) and days that any bond was purchased by the Bank of England through the QE Asset Purchase Facility (APF), or of other differences related to days of the week (Tues, Wed, Thur, Fri). The reported

\begin{tabular}{|c|c|c|c|c|c|c|c|c|c|c|c|c|c|c|}
\hline \multicolumn{15}{|c|}{ Medium-term Gilts } \\
\hline & Own Issue & Own Purchase & Issue & APF & QE Ann & MPC & N-Rock & QE1 & QE2 & QE3 & TUES & WED & THUR & FRI \\
\hline TRSY $8 \% 2021$ & -0.156 & 2.328 & 0.129 & 1.010 & 1.617 & 0.253 & 0.225 & -0.938 & -0.404 & -0.499 & -0.244 & -0.295 & -0.282 & 0.041 \\
\hline & $(-0.31)$ & (1.34) & $(0.45)$ & $\begin{array}{l}(2.71) \\
\end{array}$ & $(0.93)$ & $(0.56)$ & $(0.75)$ & $(-2.49)$ & $(-0.98)$ & $(-1.81)$ & $(-1.04)$ & $(-1.18)$ & $(-1.08)$ & $(0.16)$ \\
\hline TRSY 4\% 2022 & 0.424 & -0.054 & -0.474 & 1.285 & 1.693 & -0.439 & 0.668 & -1.156 & -0.759 & -0.623 & -0.939 & -1.047 & -0.656 & 0.103 \\
\hline & $(0.25)$ & $(-0.06)$ & $(-1.09)$ & $(2.45)$ & $(0.94)$ & $(-0.54)$ & $(0.19)$ & $(-2.38)$ & $(-1.43)$ & $(-1.64)$ & $(-1.77)$ & $(-1.80)$ & $(-1.09)$ & $(0.18)$ \\
\hline TRSY 5\% 2025 & -0.369 & 0.135 & 0.350 & 1.221 & 2.394 & 0.188 & 0.130 & -0.788 & -0.598 & -0.446 & -0.315 & -0.720 & -0.274 & 0.049 \\
\hline & $(-0.26)$ & $(0.16)$ & $(0.94)$ & $(1.96)$ & $\begin{array}{l}(1.43) \\
\end{array}$ & $(0.35)$ & $(0.38)$ & $(-1.81)$ & $(-1.09)$ & $(-1.18)$ & $(-1.01)$ & $(-2.22)$ & $(-0.83)$ & $(0.15)$ \\
\hline TRSY $4.25 \% 2027$ & 1.346 & 1.128 & 0.316 & 1.184 & 2.458 & -0.314 & 0.082 & -0.900 & -0.660 & -0.590 & -0.919 & -1.093 & -0.611 & -0.121 \\
\hline & $(1.00)$ & $(1.24)$ & $(0.65)$ & (1.79) & $(1.21)$ & $(-0.42)$ & $(0.20)$ & $(-1.70)$ & $(-1.01)$ & $(-1.27)$ & $(-2.12)$ & $(-2.39)$ & $(-1.31)$ & $(-0.26)$ \\
\hline \multicolumn{15}{|c|}{$\begin{array}{ll}(1.21) & 1-.42) \\
\text { Long-term Gilts }\end{array}$} \\
\hline TRSY 6\% 2028 & 1.300 & 1.591 & 0.189 & 1.049 & 1.256 & 0.166 & -0.003 & -0.957 & -0.759 & -0.586 & -0.317 & -0.587 & -0.227 & 0.271 \\
\hline & $(0.57)$ & (1.74) & $(0.46)$ & (1.60) & $\frac{1.258)}{(0.68)}$ & $(0.30)$ & $(-0.01)$ & $(-1.88)$ & $(-1.20)$ & $(-1.35)$ & $(-0.96)$ & $(-1.69)$ & $(-0.65)$ & $\begin{array}{l}0.271) \\
(0.77)\end{array}$ \\
\hline \multirow[t]{2}{*}{ TRSY $4.75 \% 2030$} & 1.261 & 1.544 & -0.151 & 1.708 & 0.688 & 0.049 & -0.220 & -1.422 & -1.266 & -1.202 & -1.373 & -1.282 & -0.458 & 0.227 \\
\hline & $(0.75)$ & $(1.74)$ & $(-0.26)$ & $(2.44)$ & $(0.31)$ & $(0.05)$ & $(-0.47)$ & $(-2.33)$ & $(-1.76)$ & $(-2.21)$ & $(-2.69)$ & $(-2.27)$ & $(-0.79)$ & $(0.40)$ \\
\hline \multirow[t]{2}{*}{ TRSY $4.25 \% 2032$} & 0.655 & 1.324 & 0.272 & 1.485 & 1.653 & 0.069 & -0.070 & -1.133 & -1.008 & -0.710 & -0.310 & -0.704 & -0.119 & 0.417 \\
\hline & $(0.31)$ & $(1.20)$ & $(0.58)$ & $(2.03)$ & $(0.81)$ & $(0.11)$ & $(-0.17)$ & $(-1.98)$ & $(-1.30)$ & $(-1.43)$ & $(-0.81)$ & $(-1.79)$ & $(-0.30)$ & $(1.04)$ \\
\hline \multirow[t]{2}{*}{ TRSY $4.25 \% 2036$} & -0.614 & 0.400 & 0.286 & 1.991 & $\frac{1.041}{2.241}$ & 0.010 & -0.101 & -1.085 & -1.216 & $\begin{array}{l}.4768 \\
-0.768\end{array}$ & $\begin{array}{l}-0.303 \\
\end{array}$ & -0.819 & $\begin{array}{l}-0.082 \\
\end{array}$ & 0.443 \\
\hline & $(-0.26)$ & $(0.33)$ & $(0.57)$ & (2.51) & (1.16) & $(0.01)$ & $(-0.23)$ & $(-1.79)$ & $(-1.48)$ & $(-1.42)$ & $(-0.72)$ & $(-1.93)$ & $(-0.19)$ & (1.03) \\
\hline \multirow[t]{2}{*}{ TRSY $4.75 \% 2038$} & -1.793 & 2.044 & 0.378 & 1.703 & 1.813 & -0.160 & -0.091 & -1.211 & -1.331 & -0.911 & -0.583 & -0.809 & -0.047 & 0.450 \\
\hline & $(-1.36)$ & $(1.75)$ & $(0.72)$ & (2.12) & $(0.79)$ & $(-0.23)$ & $(-0.21)$ & $(-1.91)$ & $(-1.59)$ & $(-1.67)$ & $(-1.42)$ & $(-1.96)$ & $(-0.11)$ & (1.06) \\
\hline \multirow[t]{2}{*}{ TRSY $4.25 \% 2039$} & -1.887 & 2.893 & -0.638 & 1.641 & 1.065 & -0.875 & 4.828 & -1.376 & -1.483 & -1.336 & $\frac{1.47}{-2.628}$ & -2.223 & -1.219 & 0.029 \\
\hline & $(-1.41)$ & $(2.25)$ & $(-0.84)$ & (2.02) & $(0.34)$ & $(-0.60)$ & $(0.33)$ & $(-1.92)$ & $(-1.71)$ & $(-2.06)$ & $(-3.52)$ & $(-3.06)$ & $(-1.53)$ & $\begin{array}{l}0.02 \\
(0.04)\end{array}$ \\
\hline \multirow[t]{2}{*}{ TRSY $4.5 \% 2042$} & -1.327 & 2.745 & -0.168 & 1.810 & 1.945 & -1.053 & -0.324 & -1.420 & -1.741 & -1.203 & -1.852 & -1.797 & -0.151 & 0.246 \\
\hline & $(-0.54)$ & (2.10) & $\frac{0.100}{(-0.23)}$ & $(2.02)$ & $\frac{1.547)}{(0.77)}$ & $\frac{1.057)}{(-0.97)}$ & $(-0.64)$ & $\frac{1.420}{(-1.96)}$ & $(-1.83)$ & $\frac{1.205}{(-1.70)}$ & $\frac{1.052}{(-2.82)}$ & $(-2.72)$ & $(-0.23)$ & $\begin{array}{l}0.240 \\
(0.37)\end{array}$ \\
\hline \multirow[t]{2}{*}{ TRSY $4.25 \% 2046$} & -1.508 & 2.652 & 0.175 & 1.657 & 2.319 & -0.968 & -0.110 & -1.134 & -1.511 & -1.032 & -1.384 & -1.513 & -0.280 & 0.330 \\
\hline & $(-0.61)$ & $(1.92)$ & $(0.27)$ & $(1.76)$ & $(0.91)$ & $(-0.98)$ & $(-0.22)$ & $(-1.55)$ & $(-1.49)$ & $(-1.51)$ & $(-2.25)$ & $(-2.52)$ & $(-0.45)$ & $(0.54)$ \\
\hline \multirow{2}{*}{ TRSY $4.25 \% 2049$} & 3.018 & 3.299 & -0.645 & 1.877 & 2.296 & -0.997 & 0.003 & -1.530 & -1.625 & -1.214 & -2.721 & -1.834 & -0.890 & 0.312 \\
\hline & $(0.75)$ & (2.19) & $(-0.80)$ & $(1.91)$ & $(0.72)$ & $(-0.65)$ & $(0.00)$ & $(-1.85)$ & $(-1.57)$ & $(-1.58)$ & $(-3.15)$ & $(-2.20)$ & $(-0.99)$ & $(0.34)$ \\
\hline \multirow[t]{2}{*}{ TRSY $4.25 \% 2055$} & 3.607 & 2.868 & -0.106 & 1.532 & 3.230 & -0.641 & -0.209 & -0.988 & -1.566 & -0.901 & -0.857 & -1.091 & -0.116 & 0.655 \\
\hline & $(1.27)$ & $(1.83)$ & $(-0.16)$ & (1.48) & (1.25) & $(-0.63)$ & $(-0.40)$ & $(-1.27)$ & $(-1.38)$ & $(-1.20)$ & $(-1.41)$ & $(-1.85)$ & $(-0.19)$ & $(1.09)$ \\
\hline \multirow{2}{*}{ Gilt Index } & & & -0.478 & 2.092 & -3.357 & 0.411 & -0.073 & -0.84 & -1.105 & -0.762 & -0.521 & -0.692 & -1.106 & -0.678 \\
\hline & & & $(-1.00)$ & $\begin{array}{l}(2.79) \\
\end{array}$ & $(-1.10)$ & $(0.55)$ & $(-0.17)$ & $(-1.46)$ & $(-1.28)$ & $(-1.40)$ & $(-1.40)$ & $(-1.76)$ & $(-2.67)$ & $(-1.59)$ \\
\hline
\end{tabular}
estimates of the parameters $\gamma_{i}, i=1,2, \ldots, 14$, have all been multiplied by $10^{3}$. Below the parameter estimates are robust t-statistics in parentheses. The table is divided into the official maturity classifications at the end of the sample. 


\section{Table 6: Estimated parameters for a model of conditional volatility with $\mathrm{QE}$ and bond market event indicators}

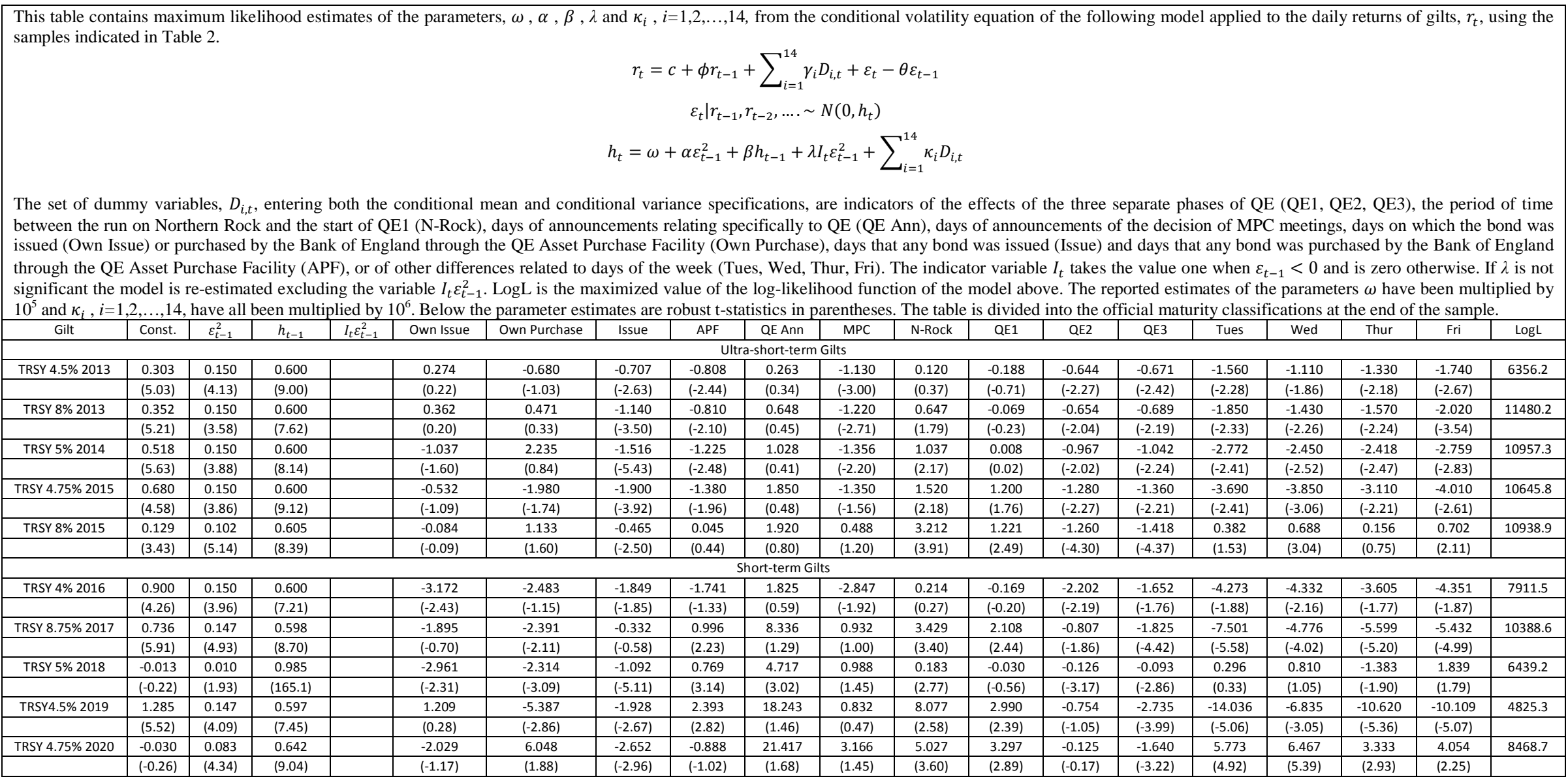


Table 6 cont.: Estimated parameters for a model of conditional volatility with $\mathrm{QE}$ and bond market event indicators

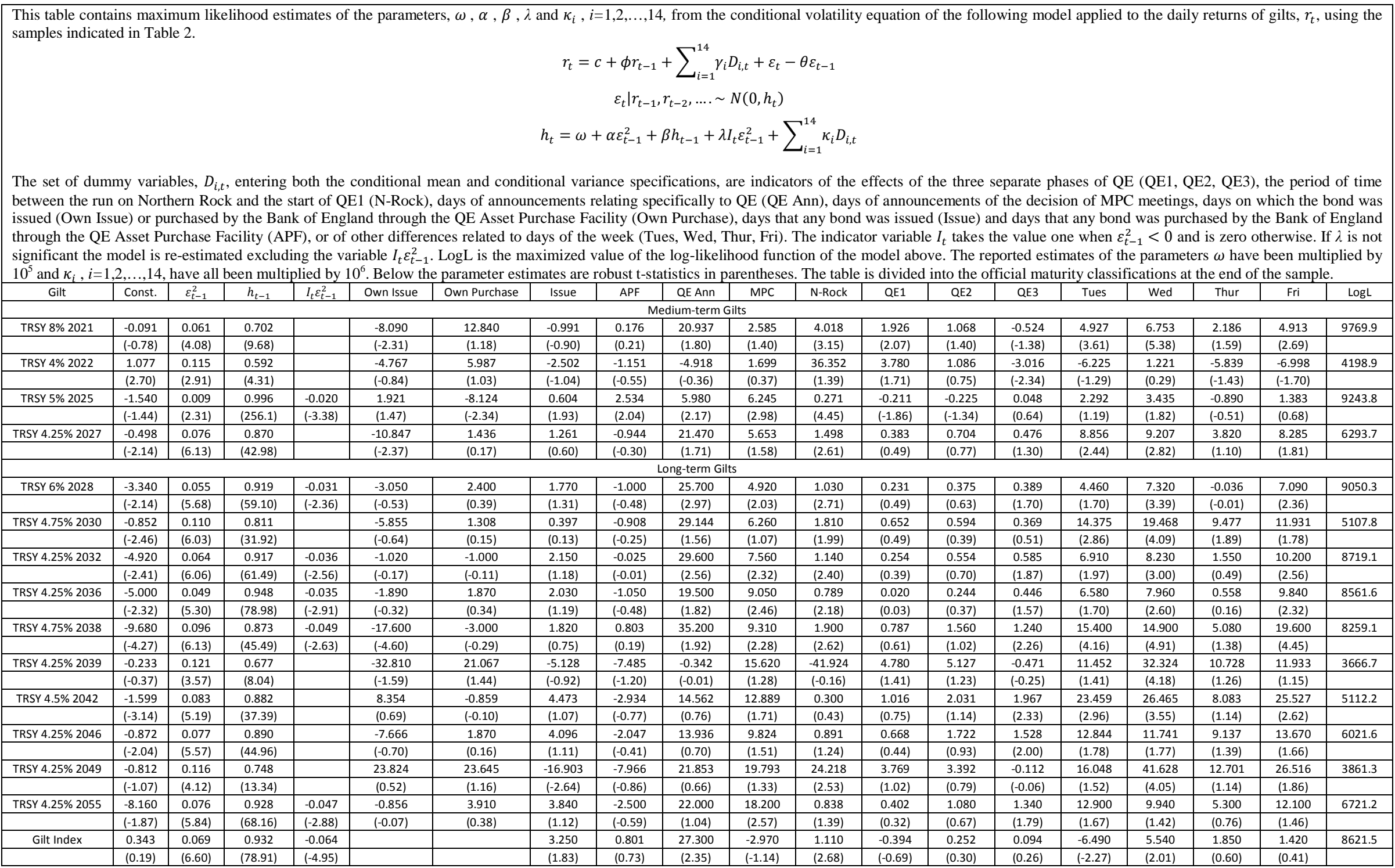




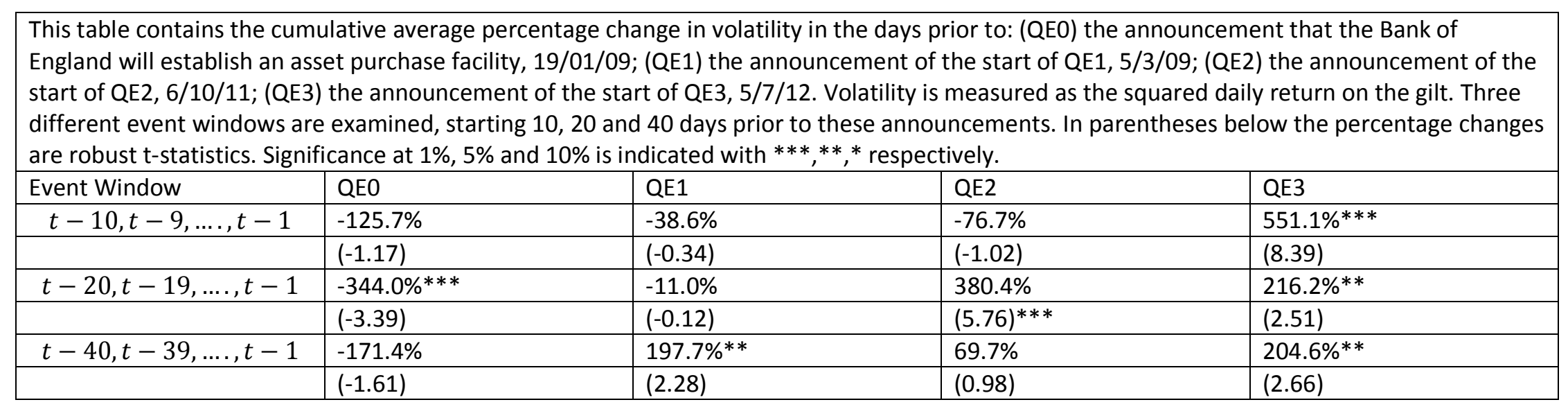




\section{Table 8: Cross section determinants of bond volatility sensitivities}

This table reports the results of cross section regressions ( 24 observations) to explain the sensitivities of bond volatility to the indicator variables in Table 6 above. For each bond, its estimated coefficient (standardized by its standard error) for a given factor is regressed against its coupon, time to maturity, and other characteristics, such as the amount of APF activity it experienced (Purchases), the average Excess Supply at each of its own Purchase auctions (Excess Supply), the size of the issue (Size) and the change in the size of the issue through the sample (Issuance). A positive estimated coefficient in these regressions means that this characteristic of the bond makes it more likely that its volatility will increase when experiencing the particular event or QE period. Heteroskedasticity and autocorrelation robust t-statistics are reported below each coefficient. P-Val(Wald) is the p-value of a robust F-statistic for the overall significance of the regression.

\begin{tabular}{|c|c|c|c|c|c|c|c|}
\hline \multicolumn{8}{|c|}{ Panel A: Phases of QE and Purchase Activity } \\
\hline & Const. & Coupon & Maturity & Purchases & Excess Supply & $\bar{R}^{2}$ & P-Val (Wald) \\
\hline \multirow[t]{2}{*}{ QE1 } & -3.694 & 0.480 & $<0.001$ & 2.581 & -0.453 & 0.277 & $<0.001$ \\
\hline & $(-8.19)$ & $(5.43)$ & $(4.56)$ & $(4.41)$ & $(-3.26)$ & & \\
\hline \multirow[t]{2}{*}{ QE2 } & -2.398 & -0.045 & $<0.001$ & 2.450 & 0.505 & 0.592 & $<0.001$ \\
\hline & $(-2.31)$ & $(-0.23)$ & $(2.87)$ & $(5.78)$ & (3.28) & & \\
\hline \multirow[t]{2}{*}{ QE3 } & 1.524 & -0.462 & $<0.001$ & -1.442 & 0.854 & 0.688 & $<0.001$ \\
\hline & $(1.14)$ & $(-3.06)$ & $(1.59)$ & $(-1.43)$ & $(3.93)$ & & \\
\hline \multirow[t]{2}{*}{ Northern Rock } & 0.434 & 0.353 & $<0.001$ & & & 0.147 & 0.020 \\
\hline & $(0.46)$ & (2.69) & $(-0.33)$ & & & & \\
\hline \multirow[t]{2}{*}{ Own Purchases } & -1.209 & 0.130 & $<0.001$ & 0.872 & 0.691 & 0.158 & 0.002 \\
\hline & $(-1.15)$ & $(0.92)$ & $(-0.09)$ & $(1.32)$ & $(2.07)$ & & \\
\hline \multirow[t]{2}{*}{ APF Days } & -5.463 & 0.513 & $<0.001$ & 3.132 & -0.641 & 0.208 & $<0.001$ \\
\hline & $(-4.42)$ & $(5.68)$ & $(2.55)$ & $(2.39)$ & $(-1.81)$ & & \\
\hline \multicolumn{8}{|c|}{ Panel B: Announcements relating to QE } \\
\hline & Const. & Coupon & Maturity & Purchases & Issuance & $\bar{R}^{2}$ & P-Val (Wald) \\
\hline \multirow[t]{2}{*}{ MPC } & -1.527 & 0.085 & $<0.001$ & 3.756 & -2.068 & 0.529 & 0.004 \\
\hline & $(-0.55)$ & $(0.33)$ & (4.29) & (2.19) & $(-1.49)$ & & \\
\hline \multirow[t]{2}{*}{ QEANN } & 3.211 & -0.176 & $<0.001$ & 0.162 & -1.566 & $<0.001$ & 0.697 \\
\hline & $(1.85)$ & $(-1.07)$ & $(0.32)$ & $(0.12)$ & $(-1.29)$ & & \\
\hline \multicolumn{8}{|c|}{ Panel C: Issuance Activity } \\
\hline & $\mathrm{C}$ & Coupon & Maturity & Issuance & Size & $\bar{R}^{2}$ & P-Val (Wald) \\
\hline \multirow[t]{2}{*}{ Own Issue } & 6.465 & -0.561 & $<0.001$ & -5.144 & $|<|-0.001$ & $<0.001$ & $<0.023$ \\
\hline & $(1.63)$ & $(-1.69)$ & $(0.34)$ & $(-2.27)$ & $(-1.29)$ & & \\
\hline \multirow[t]{2}{*}{ Issue } & 4.499 & -0.895 & $<0.001$ & -5.083 & $|<|-0.001$ & 0.366 & $<0.001$ \\
\hline & (1.19) & $(-2.11)$ & (3.22) & $(-1.68)$ & $(-0.31)$ & & \\
\hline
\end{tabular}


Table 9: Granger-causality tests between gilt volatility and the money supply

This table contains the Wald test p-values for bivariate Granger causality tests between the monthly volatility of the named gilt and the monthly money supply (UK MO). The testing procedure follows Toda and Yamamoto (1995) and ensures that the Wald test statistics are asymptotically distributed chi-squared. Gilt volatility is the standard deviation of the daily returns from the day after the prior month money supply data release until the day of the current month money supply release. Money supply data were obtained from the Bank of England's data service.

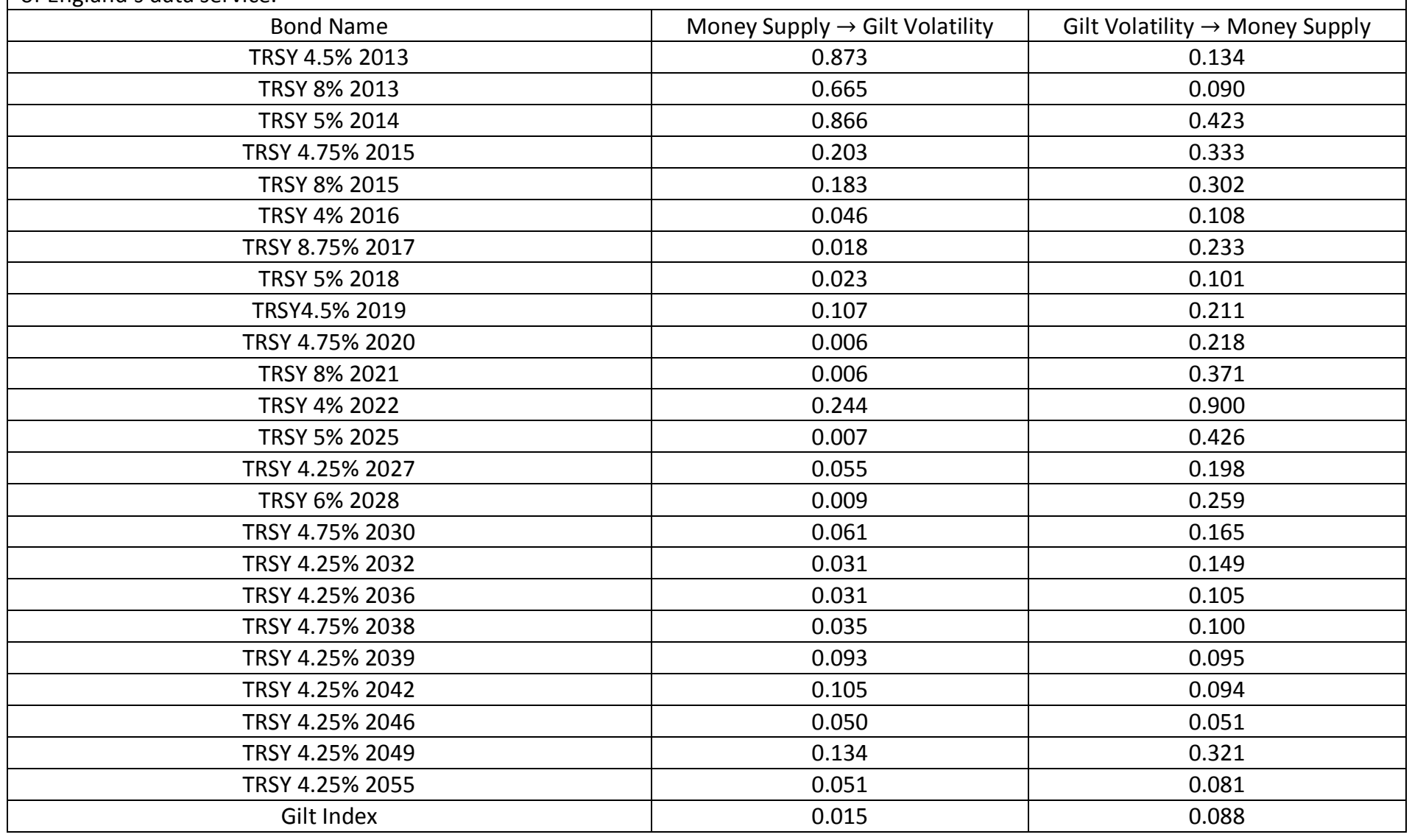


Figure 1: Gilt gross and net issuance

This figure shows the annual total gilt gross and net issuance from 1990/91 to 2013/14. (Source: UK DMO)

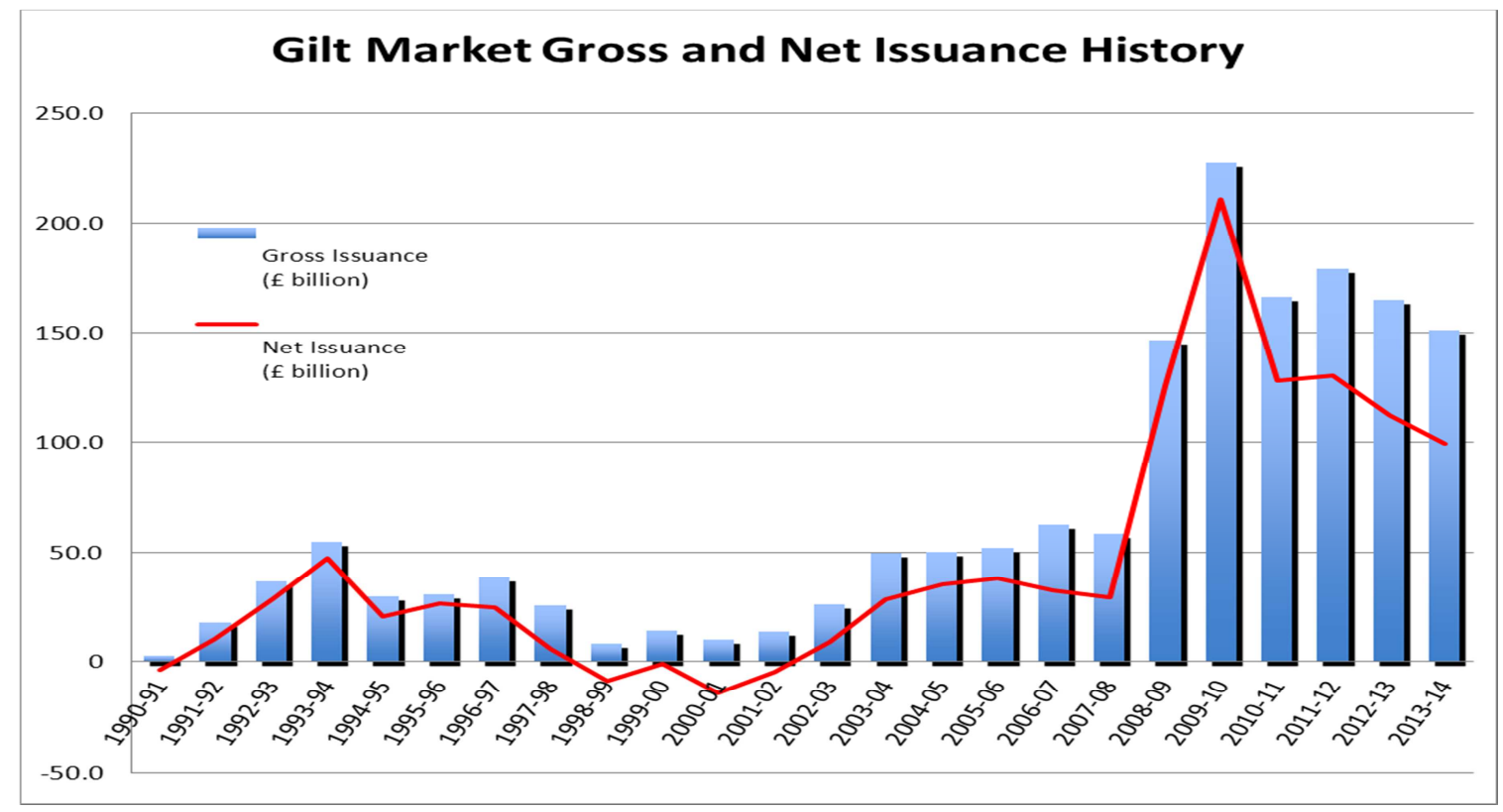

Figure 2: Gilt issuance and Purchase Auctions

This figure shows the monthly total gilt issuance and total purchase auction payments for the gilt market through the sample period. (Source: Bank of England and UK DMO).

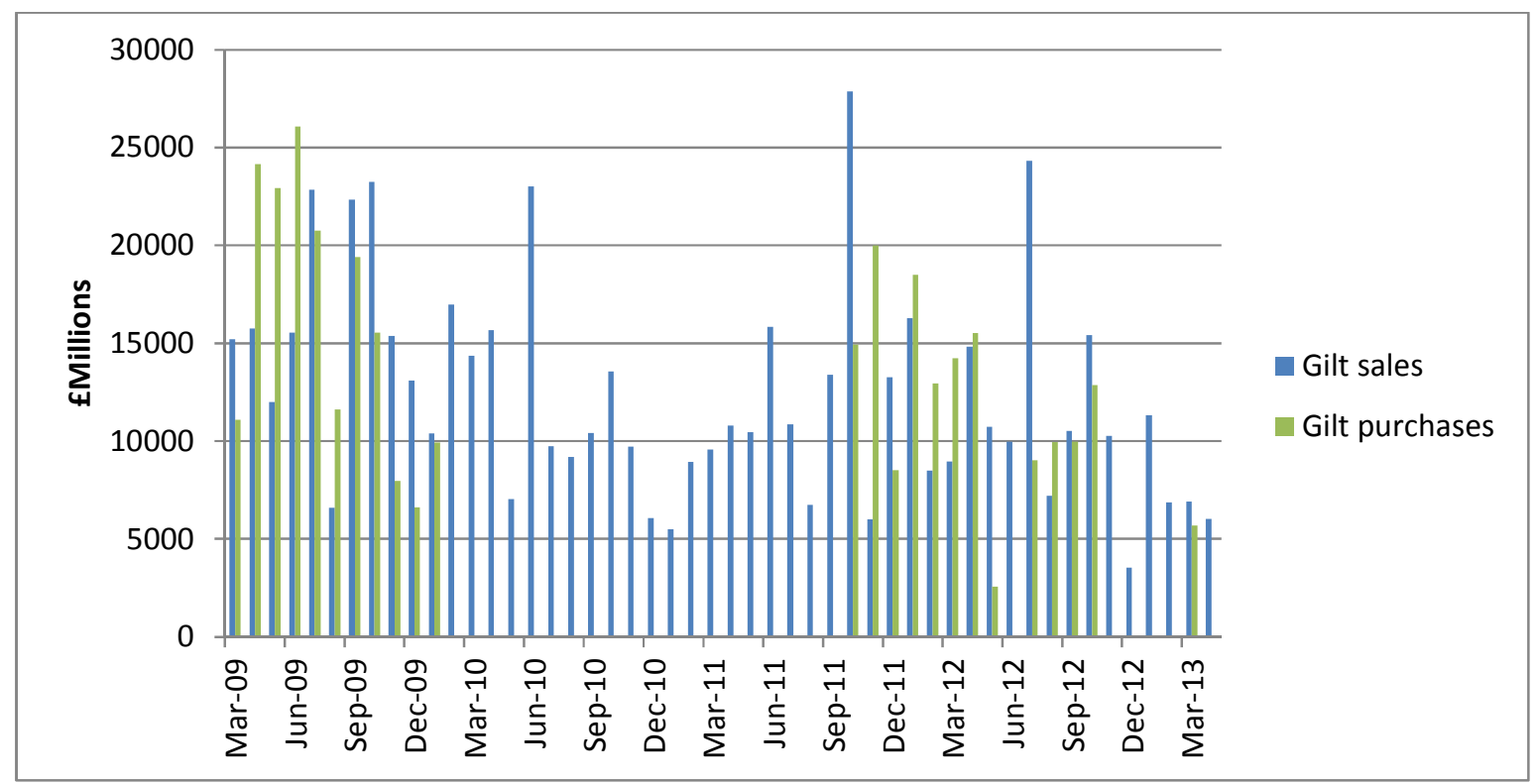


Figure 3: Gilt Issuance by day of the week

This figure shows the distribution of gilt issuance across the days of the week for each of the sub-samples. The bars are ratio of the number of times that weekday was used for issuance to the total number of that weekday in the sub-sample. For example, over 45 percent of all Wednesdays during the QE1 phase experienced gilt issuance. (Source: UK DMO)

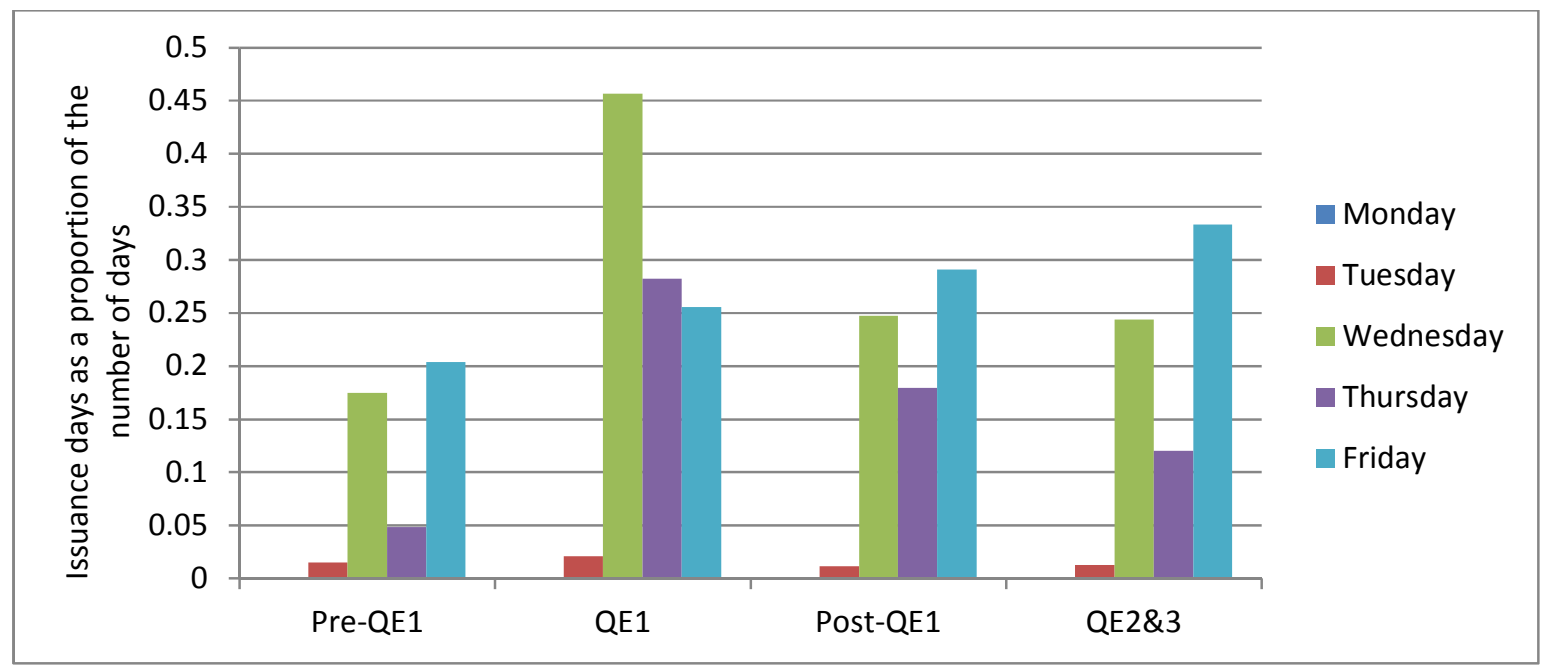

Figure 4: Gilt Purchase Auctions by day of the week

This figure shows the distribution of gilt purchase auctions across the days of the week for each of the sub-samples. The bars are ratio of the number of times that weekday was used for purchase auctions to the total number of that weekday in the sub-sample. For example, almost 80 percent of all Wednesdays during the QE1 phase experienced gilt purchase auctions. (Source: Bank of England).

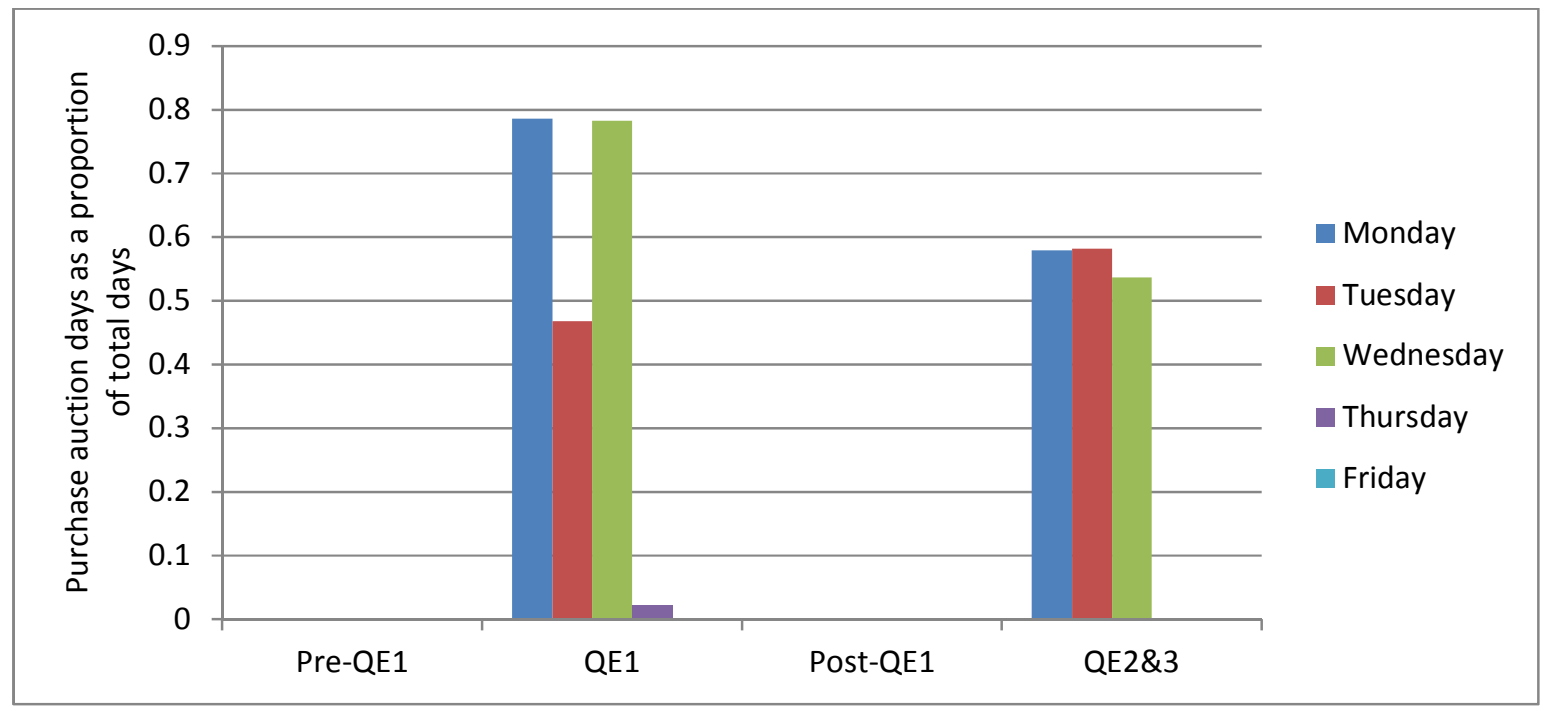


Figure 5: Estimated Conditional Volatility for Gilt Returns

This figure contains examples, for each maturity range (Ultra-short, Short, Medium and Long), of the time series of conditional volatility for gilt returns over the sample period.

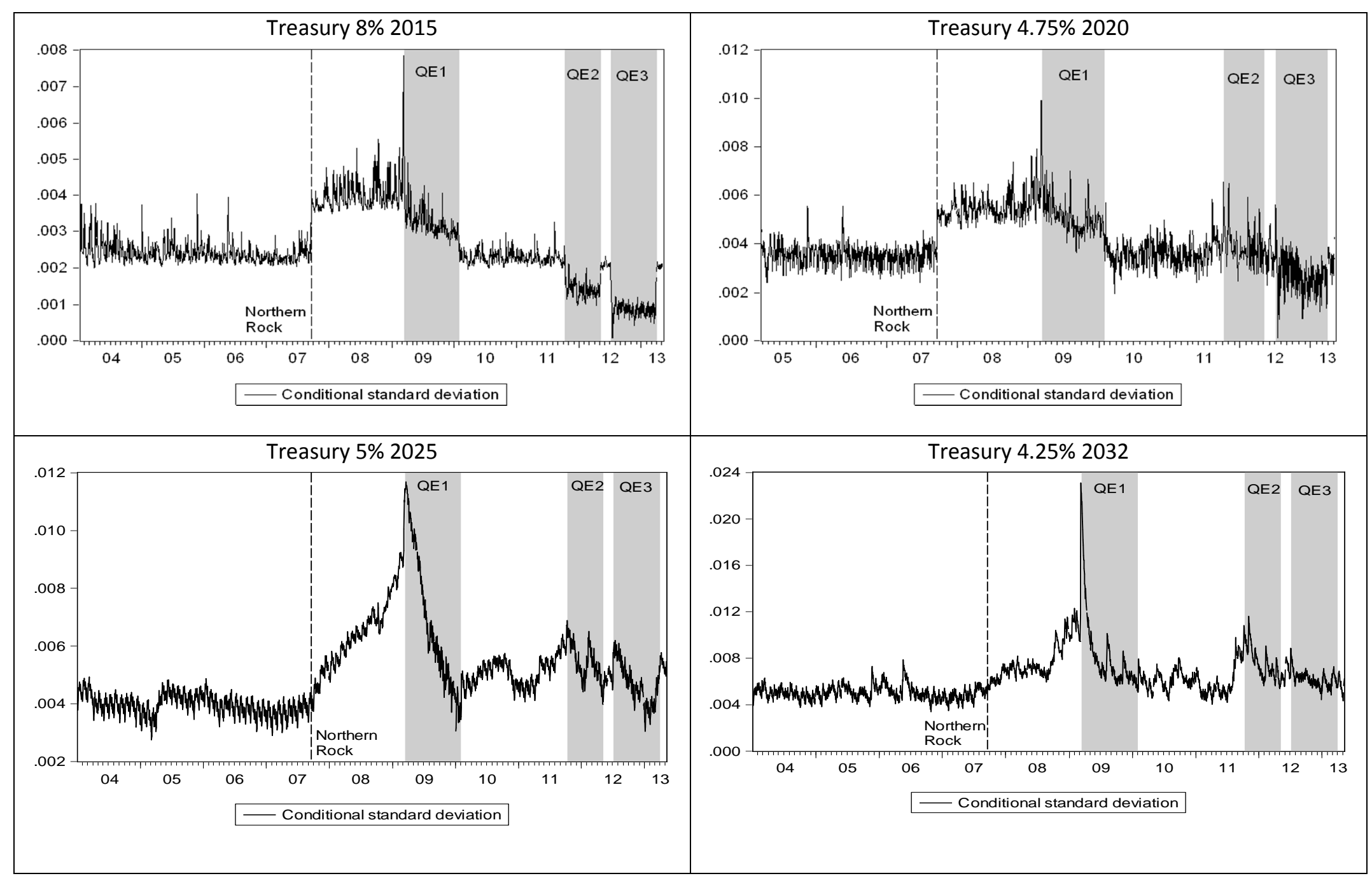

